\author{
Gabriella Duarte Queiroz Leite
}

\title{
Efeitos crônicos da Angiotensina II sobre a atividade e expressão da isoforma 3 do trocador $\mathrm{Na}^{+} / \mathrm{H}^{+}$
}

Tese apresentada ao Programa de PósGraduação em Fisiologia Humana do Instituto de Ciências Biomédicas da Universidade de São Paulo, para a obtenção do título de Doutor em Fisiologia Humana.

Área de concentração: Fisiologia Humana

Orientadora: Profa. Dra. Nancy Amaral Rebouças

São Paulo

2011 


\section{RESUMO}

QUEIROZ-LEITE, G. D. Efeitos crônicos da Angiotensina II sobre a atividade e expressão da isoforma 3 do trocador $\mathbf{N a}^{+} / \mathbf{H}^{+}$(NHE3). 2011. $119 \mathrm{f}$. Tese (Doutorado em Fisiologia Humana) - Instituto de Ciências Biomédicas, Universidade de São Paulo, São Paulo, 2011.

NHE3 é principalmente expresso em células epiteliais renais e intestinais e é responsável pela maior parte da reabsorção de $\mathrm{Na}^{+}$em túbulos proximais. Essa proteína é modulada por diversos agentes e, entre eles, está a Ang II. É sabido que a Ang II modula agudamente a atividade de NHE3 de forma bimodal. O objetivo deste trabalho foi avaliar os efeitos crônicos da Ang II sobre a atividade, expressão e atividade promotora de transcrição de NHE3. A atividade de NHE3 foi avaliada por microscopia de fluorescência com a sonda BCECF. A taxa de recuperação do $\mathrm{pH}_{\mathrm{i}}$ após pulso ácido foi analisada na presença de veículo, HOE 694 (inibidor de NHE1 e NHE2), bafilomicina (inibidor de $\mathrm{V}-\mathrm{H}^{+}$ATPase) e S3226 (inibidor específico de NHE3). Só houve redução significativa do $\mathrm{pH}_{\mathrm{i}}$ na presença de $\mathrm{S} 3226$ e não houve recuperação na ausência de $\mathrm{Na}^{+}$extracelular. Células foram expostas por $24 \mathrm{~h}$ a Ang II em curva dose-resposta $\left(10^{-7} \mathrm{M}\right.$ a $\left.10^{-12} \mathrm{M}\right)$ e houve aumento significativo na taxa de recuperação do $\mathrm{pH}_{\mathrm{i}}$ apenas em células tratadas com Ang II $10^{-11} \mathrm{M}$. Experimentos de Western blot mostraram um aumento na expressão total de NHE3 na presença de Ang II e a amplificação de cDNA por PCR em tempo real mostrou um aumento nos níveis de RNAm de NHE3 na presença de Ang II. Pré-incubação com Actinomicina D (ActD) não mostrou diferença significativa entre os tempos de $1 / 2$ vida do RNAm de NHE3 de células tratadas e não tratadas com Ang II. Transfecções transitórias de quatro fragmentos da região flanqueadora 5' do gene NHE3 de rato $(-2095 /+55,-152 /+55,-85 /+31$ e $-65 /+31)$, clonados em um vetor contendo um gene repórter (Firifly Luciferase) mostraram que a atividade promotora de transcrição do fragmento $-65 /+31$ aumentou de forma significativa na presença de Ang II. Foram feitas mutações em dois sítios consensuais para a ligação dos fatores de transcrição Sp1/Egr-1 e AP2 no fragmento $-60 /+31$ e os resultados das transfecções mostraram que a mutação no sítio para ligação de Sp1/Egr-1 aboliu completamente o efeito estimulatório da Ang II, já a mutação no sítio AP2 reverteu parcialmente esse estímulo. As vias que envolvem o citocromo P450, a PI3K, a PKA e a MAPK parecem estar envolvidas no estímulo da atividade promotora de NHE3 gerado por Ang II. As vias da PLC e JAK/STAT parecem não estar envolvidas nesse processo. Pré-incubação com Losartan aboliu todos os efeitos observados. Pode-se concluir que o tratamento crônico com baixa concentração de Ang II promoveu aumento na atividade, na expressão, na quantidade de RNAm e na taxa de transcrição do gene NHE3. Parece que o sítio de ligação para os fatores de transcrição Sp1/Egr-1 está diretamente envolvido nessa resposta. A regulação crônica de NHE3 por Ang II parece ser mediada por AT1R. A capacidade da Ang II de modular a expressão gênica em situações de estímulo crônico pode representar um importante papel na regulação da reabsorção de $\mathrm{Na}^{+}$e água em túbulos proximais.

Palavras-chave: Secreção de $\mathrm{H}^{+}$. Reabsorção de $\mathrm{Na}^{+}$. Túbulo proximal. Regulação de transcrição. Sistema renina-angiotensina. 


\begin{abstract}
QUEIROZ-LEITE, G D. Chronic effects of angiotensin II on the isoform 3 of $\mathrm{Na}^{+} / \mathrm{H}^{+}$ exchanger (NHE3). 2011. 119 p. Ph. D. thesis (Human Physiology) - Instituto de Ciências Biomédicas, Universidade de São Paulo, São Paulo, 2011.

NHE3 is mainly expressed at the apical membrane of renal and intestinal cells. This protein is the major responsible for the sodium reabsorption in renal proximal tubules. A variety of stimuli can modulate NHE3 activity, including angiotensin II (Ang II). Ang II exerts an acute bimodal modulation on NHE3: low concentrations stimulate the exchanger and high concentrations inhibit it. The aim of the present study was to evaluate the chronic effects of Ang II on NHE3 activity, transcription and expression. The NHE3 activity was evaluated by measuring pHi recovery after an acid load. The $\mathrm{pHi}$, measured by fluorescence microscopy with the dye BCECF, was evaluted in the presence of vehicle, HOE $69420 \mu \mathrm{M}$ (NHE1 and NHE2 inhibitor), bafilomycin $10^{-7} \mathrm{M}\left(\mathrm{V}-\mathrm{H}^{+}\right.$ATPase inhibitor) and S3226 100 $\mu \mathrm{M}$ (NHE3 specific inhibitor). Only the $\mathrm{S} 3226$ treated group presented a significant lower rate of $\mathrm{pH}_{\mathrm{i}}$ recovery and there was no recovery in absence of extracellular $\mathrm{Na}^{+}$. Cells were treated with Ang II $10^{-7} \mathrm{M}$ to $10^{-12} \mathrm{M}$ for $24 \mathrm{~h}$, and there was a significant increase in $\mathrm{pH}_{\mathrm{i}}$ recovery rate when cells were treated with Ang II $10^{-11}$ M. NHE3-protein and NHE3-mRNA were increased after $24 \mathrm{~h}$ in presence of Ang II $10^{-11} \mathrm{M}$, as determined by Western immuno-blotting and RTPCR respectively. NHE3 mRNA $1 / 2$ life in cells previously incubated with $5 \times 10^{-6} \mathrm{M}$ Actinomycin D (ActD) was not affected by Ang II treatment. The promoter activity of four fragments of the 5' flanking sequence of rat NHE3 gene $(-2095 /+55,-152 /+55,-85 /+31$ e $65 /+31$ ), cloned into a vector containing a reporter gene (Firifly Luciferase) was evaluated after transient transfection, and the promoter activity of the fragment $-65 /+31$ was significant increased in the presence of Ang II. The fragment -60/+31was mutated at the Sp1/Egr-1 and AP2 consensual sites. Mutation at Sp1/Egr-1 site abolished the stimulatory effect of Ang II on NHE3 promoter activity, while mutation at AP2 reduced that effect. The signaling pathways involving cytochrome P450, PI3K, PKA and MAPK seem to be related with this stimulatory effect, while PLC and JAK/STAT are not related. Losartan $10^{-5} \mathrm{M}$ abolished all the observed effects. Taking all these results together, we conclude that chronic treatment with low concentration of Ang II resulted in increase of NHE3 activity, protein expression, mRNA levels and promoter activity of NHE3 gene. The Sp1/Egr-1 site seems to be directly involved in the Ang II activation of the NHE3 promoter. All the Ang II dependent effects on NHE3 were mediated through AT1R. The Ang II ability of modulating gene expression under chronic stimulation could represent an important mechanism of regulation of $\mathrm{Na}^{+}$, bicarbonate, chloride and water reabsorption in proximal tubule.
\end{abstract}

Key words: $\mathrm{H}^{+}$secretion. $\mathrm{Na}^{+}$reabsorption. Proximal tubule. Transcriptional modulation. Rennin angiotensin system. 


\section{INTRODUÇÃO}

\subsection{REVISÃO DA LITERATURA}

Os rins são constituídos de unidades funcionais chamadas néfrons e cada rim possui em torno de um milhão dessas estruturas. O néfron possui uma região glomerular, formada por um conjunto de capilares sanguíneos, responsáveis pela filtração do sangue; e uma região tubular, subdividida em regiões específicas, cujas células epiteliais apresentam variações morfológicas de acordo com sua posição ao longo de cada néfron. A região tubular dessas estruturas participa da transformação do plasma filtrado em urina, secretando e reabsorvendo substâncias de acordo com a necessidade do organismo. A figura 1 ilustra um néfron e destaca suas regiões glomerular e tubular.

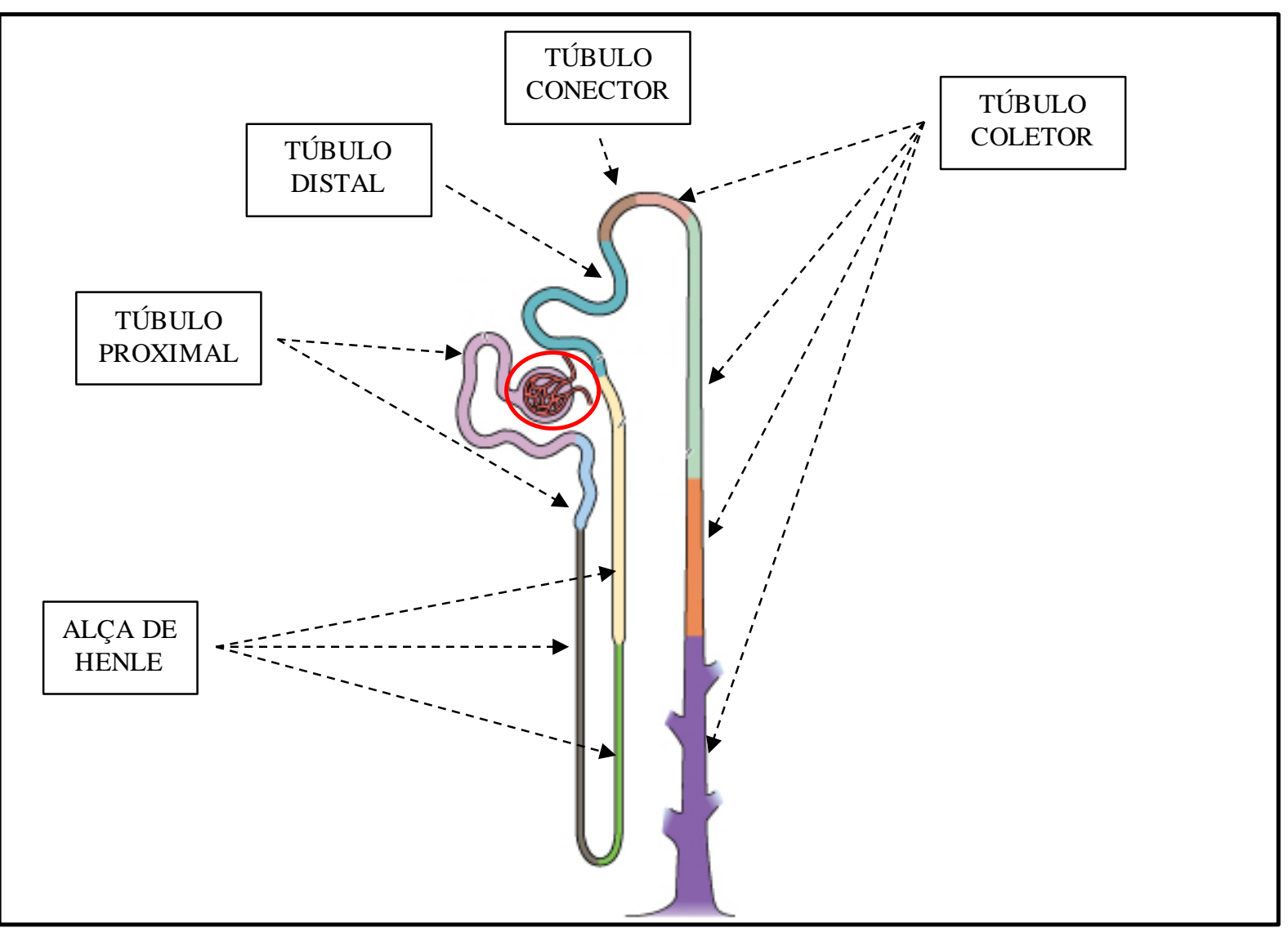

Figura 1- Subdivisões tubulares do néfron. A região circulada em vermelho corresponde à região glomerular. FONTE: modificado de Boron e Boulpaep (2005). 
O túbulo proximal renal é o principal sítio de reabsorção de água e solutos filtrados no glomérulo. Por exemplo, em indivíduos saudáveis, a glicose filtrada é totalmente reabsorvida nessa região e aproximadamente $67 \%$ do $\mathrm{Na}^{+}$filtrado volta para a circulação sanguínea nessa porção do néfron. Há uma gama de proteínas que atuam nos processos de reabsorção e secreção renais e, entre elas, está a família de trocadores $\mathrm{Na}^{+} / \mathrm{H}^{+}$(NHE). Essas proteínas medeiam a troca de um $\mathrm{Na}^{+}$extracelular por um $\mathrm{H}^{+}$intracelular e são extremamente importantes para a manutenção do balanço desse íon, assim como para a regulação do equilíbrio hídrico e ácido-básico do organismo.

\subsubsection{Trocadores $\mathrm{Na}^{+} / \mathrm{H}^{+}$}

A primeira evidência funcional de um desses transportadores foi descrita em 1976, por Murer e colaboradores. O transporte realizado pelos trocadores $\mathrm{Na}^{+} / \mathrm{H}^{+}$é dependente do funcionamento da $\mathrm{Na}^{+} / \mathrm{K}^{+}$ATPase, presente na membrana basolateral das células epiteliais. Essa proteína bombeia $3 \mathrm{Na}^{+}$para fora da célula e $2 \mathrm{~K}^{+}$para dentro, contra o gradiente de concentração desses íons. A energia necessária para que a bomba funcione contra o gradiente de concentração dos íons é proveniente diretamente da hidrólise do ATP e, portanto, essa proteína realiza transporte ativo primário. A dependência do NHE com relação à $\mathrm{Na}^{+} / \mathrm{K}^{+}$ ATPase se baseia na utilização, pelo trocador, do gradiente de $\mathrm{Na}^{+}$mantido pela $\mathrm{Na}^{+} / \mathrm{K}^{+}$ ATPase. Assim, o NHE reabsorve $\mathrm{Na}^{+}$do túbulo renal a favor do seu gradiente de concentração e elimina $\mathrm{H}^{+}$para o túbulo contra seu gradiente. Dessa forma, o NHE realiza transporte ativo secundário. A relação entre o NHE e a $\mathrm{Na}^{+} / \mathrm{K}^{+}$ATPase está ilustrada na figura 2. 


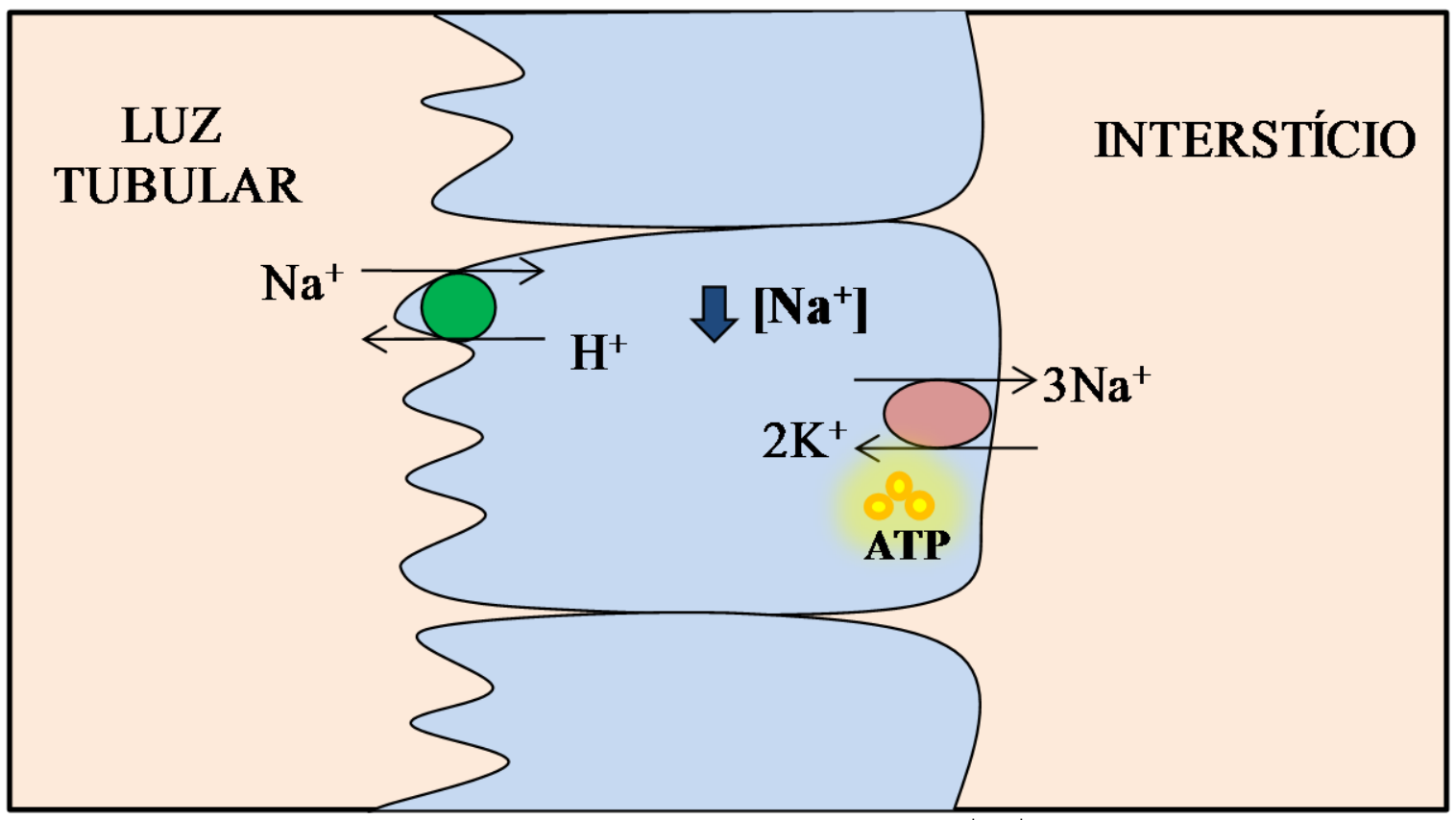

Figura 2- Representação esquemática da relação entre o $\mathrm{NHE}$ e a $\mathrm{Na}^{+} / \mathrm{K}^{+}$ATPase em células epiteliais renais.

A primeira isoforma de NHE a ter sua sequência primária identificada, NHE1, foi clonada em 1989 pelo grupo do pesquisador Pouyssegur (SARDET; FRANCHI; POUYSSEGUR, 1989). Desde então, nove isoformas dessa proteína já foram descritas e bem caracterizadas em mamíferos e, recentemente, a décima isoforma foi identificada e parece ser expressa apenas em osteoclastos (BRETT; DONOWITZ; RAO, 2005; LEE et al., 2008). A maioria das isoformas possui distribuição tecidual específica, ao contrário de NHE1, que é a isoforma ubíqua, expressa na membrana plasmática de praticamente todas as células eucarióticas (ALEXANDER; GRINSTEIN, 2006). Dentre as isoformas, NHE1 é uma das principais proteínas que mantêm a estabilidade do $\mathrm{pH}$ e do volume intracelulares e NHE3 é a principal proteína relacionada com a (re)absorção de $\mathrm{Na}^{+}, \mathrm{HCO}_{3}{ }^{-}$e fluído em células epiteliais de túbulo proximal e intestino.

Os trocadores $\mathrm{Na}^{+} / \mathrm{H}^{+}$são proteínas integrais de membrana formadas por doze domínios transmembrana relativamente conservados na porção $\mathrm{N}$-terminal e uma cauda Cterminal hidrofílica que varia em tamanho e constituição de aminoácidos entre as diferentes isoformas. Os sítios de translocação dos íons possivelmente envolvem os domínios transmembrana 4, 5, 8, 9 e 10 (ORLOWSKI; GRISTEIN., 2004). A região C-terminal possui sítios reconhecidamente fosforilados e sequências que determinam a interação com outras proteínas, funcionando como porção regulatória da atividade do trocador. Há também sítios alostéricos para $\mathrm{H}^{+}$expostos à face intracelular, ou seja, a concentração de $\mathrm{H}^{+}$intracelular modula a atividade do trocador e essa modulação não envolve o sítio responsável pela 
translocação do $\mathrm{H}^{+}$em troca por $\mathrm{Na}^{+}$. Há aumento da atividade do NHE quando ocorre queda do $\mathrm{pH}$ intracelular $\left(\mathrm{pH}_{\mathrm{i}}\right)$ (ARONSON; NEE; SUHM, 1982). A figura 3 representa um esquema da organização topológica de NHE1.

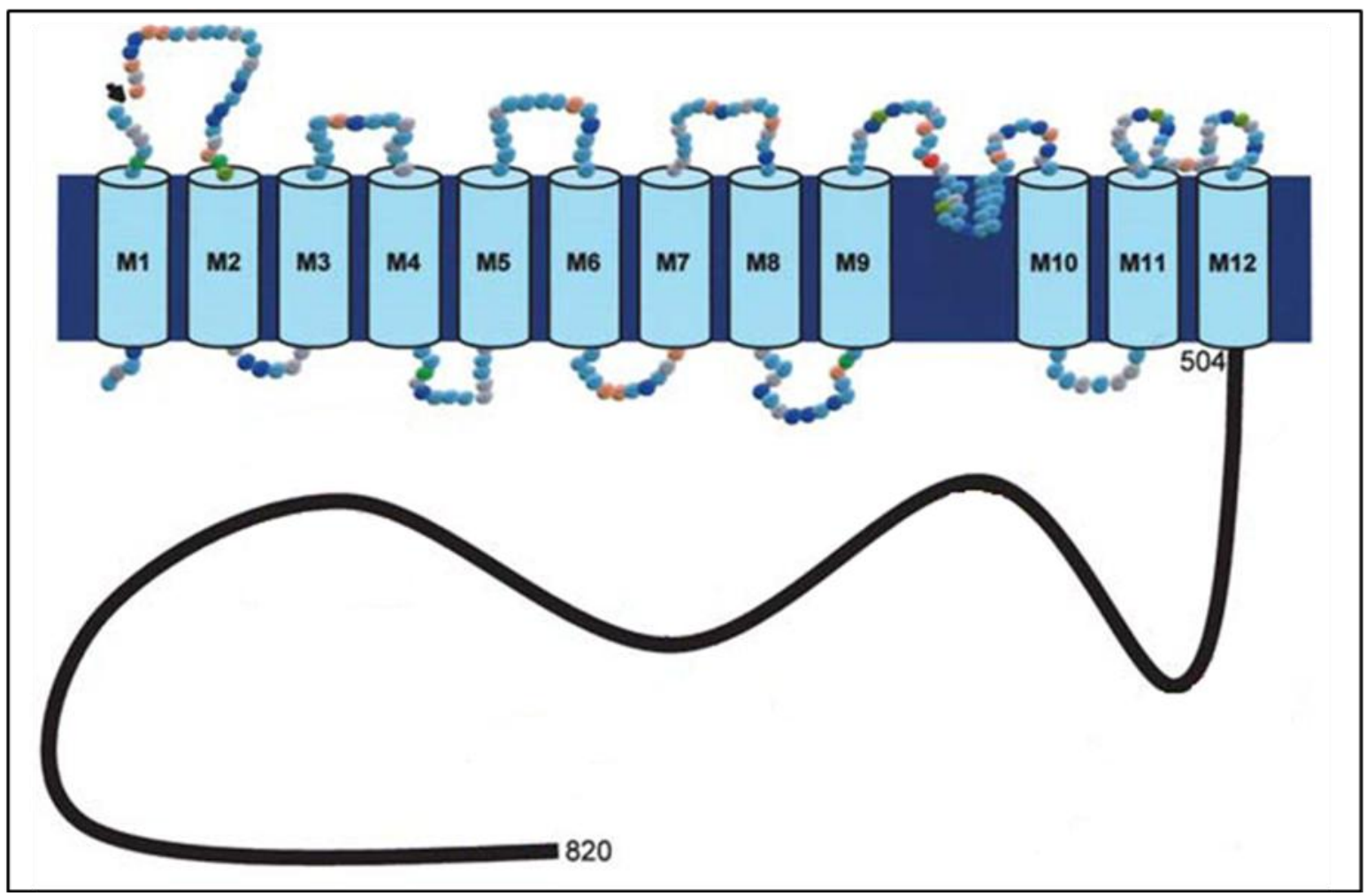

Figura 3- Esquema da organização topológica de NHE1.

FONTE: (ZACHOS et al., 2005), modificado.

As isoformas de NHE são inibidas por algumas classes de agentes farmacológicos, entre eles o diurético amiloride, seus análogos e derivados de benzyolguanidinium (como HOE 642 e HOE 694). A sensibilidade das diferentes isoformas de NHE a esses componentes é variável, sendo que NHE1 e 2 são as mais sensíveis (ORLOWSKI; GRISTEIN, 2004). Em 1998, Schwark e colaboradores sintetizaram um antagonista preferencial para NHE3, o S3226, feito que facilitou muito o estudo em células que expressam mais de uma isoforma do trocador (SCHWARK et al., 1998)

As isoformas NHE1 - 5 são expressas na membrana plasmática, as isoformas NHE6, 7 e 9 são expressas em organelas celulares e há controvérsias sobre a localização de NHE8, pois apesar de possuir maior similaridade com NHEs presentes em organelas, ele parece estar presente na membrana plasmática (DONOWITZ; LI, 2007). As isoformas expressas na membrana plasmática podem ser residentes, como NHE1, 2 e 4, ou podem reciclar entre a membrana celular e os compartimentos endossomais, como NHE3 e 5. A reciclagem entre a 
membrana plasmática e esses compartimentos é uma forma de regular a atividade dessas proteínas.

\subsubsection{NHE3}

A proteína NHE3 possui 832 aminoácidos e tem peso molecular aproximado de 87 kDa. É uma proteína abundantemente expressa em membrana apical de células epiteliais renais e possui um papel fundamental na reabsorção de $\mathrm{Na}^{+}, \mathrm{HCO}_{3}^{-}, \mathrm{Cl}^{-}$e água, principalmente no segmento proximal, apesar de ser encontrada também no ramo espesso ascendente da Alça de Henle. Essa isoforma também é muito expressa em células epiteliais intestinais e, em menor quantidade, em outras regiões do organismo, como em alguns grupos de neurônios e na bexiga (DONOWITZ; LI, 2007). A importância do NHE3 para a manutenção do equilíbrio hidroeletrolítico e ácido-básico foi bem demonstrada por Schultheis e colaboradores em estudos com camundongos knockout. Esses animais NHE3-KO apresentaram deficiência na reabsorção tubular, diarréia, acidose e queda na pressão arterial quando comparados aos animais controle (SCHULTHEIS et al., 1998).

\subsubsection{FUNÇÕES DE NHE3 NO RIM}

O NHE3 presente na membrana apical das células dos túbulos proximais é o responsável pela reabsorção de $\sim 70 \%$ do $\mathrm{Na}^{+}$filtrado. $\mathrm{Na}$ Alça de Henle há reabsorção de $25 \%$ do $\mathrm{Na}^{+}$filtrado, principalmente pelo cotransportador $\mathrm{Na}^{+} / \mathrm{K}^{+} / 2 \mathrm{Cl}^{-}$. O túbulo distal é o responsável pela regulação fina da excreção de $\mathrm{Na}^{+}$e os transportadores mais importantes dessa região são o cotransportador $\mathrm{Na}^{+} / \mathrm{Cl}^{-}$e o canal epitelial para $\mathrm{Na}^{+}(\mathrm{ENaC})$.

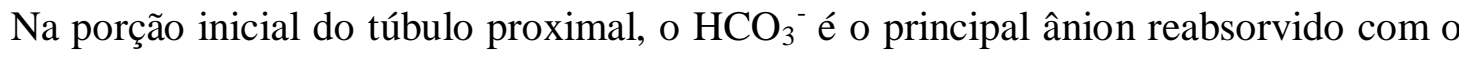
$\mathrm{Na}^{+}$. A reabsorção desse ânion é indireta, pois para cada $\mathrm{H}^{+}$secretado pelo $\mathrm{NHE} 3$, um $\mathrm{HCO}_{3}{ }^{-}$ é formado no meio intracelular. Na luz tubular, a isoforma IV da anidrase carbônica catalisa a formação de $\mathrm{OH}^{-}$e $\mathrm{CO}_{2}$ a partir do $\mathrm{HCO}_{3}{ }^{-}$filtrado e o $\mathrm{H}^{+}$secretado pelo NHE3 se une ao radical $\mathrm{OH}^{-}$formando $\mathrm{H}_{2} \mathrm{O}$. $\mathrm{O} \mathrm{CO}_{2}$ é um gás lipossolúvel e pode atravessar a membrana celular. Uma vez dentro da célula, o $\mathrm{CO}_{2}$ se une aos radicais $\mathrm{OH}^{-}$formando $\mathrm{HCO}_{3}{ }^{-}$, reação catalisada pela isoforma II da anidrase carbônica. Assim, para cada $\mathrm{H}^{+}$secretado pelo NHE3 há consumo de um $\mathrm{HCO}_{3}{ }^{-}$na luz tubular e formação de um $\mathrm{HCO}_{3}{ }^{-}$intracelular, o que corresponde à reabsorção de um $\mathrm{HCO}_{3}{ }^{-}$. A secreção de $\mathrm{H}^{+}$atrelada à reabsorção de $\mathrm{HCO}_{3}{ }^{-}$ 
torna o NHE3 uma das proteínas mais importantes para a manutenção do equilíbrio ácidobásico do organismo. A reabsorção indireta de $\mathrm{HCO}_{3}{ }^{-}$está ilustrada na figura 4 .

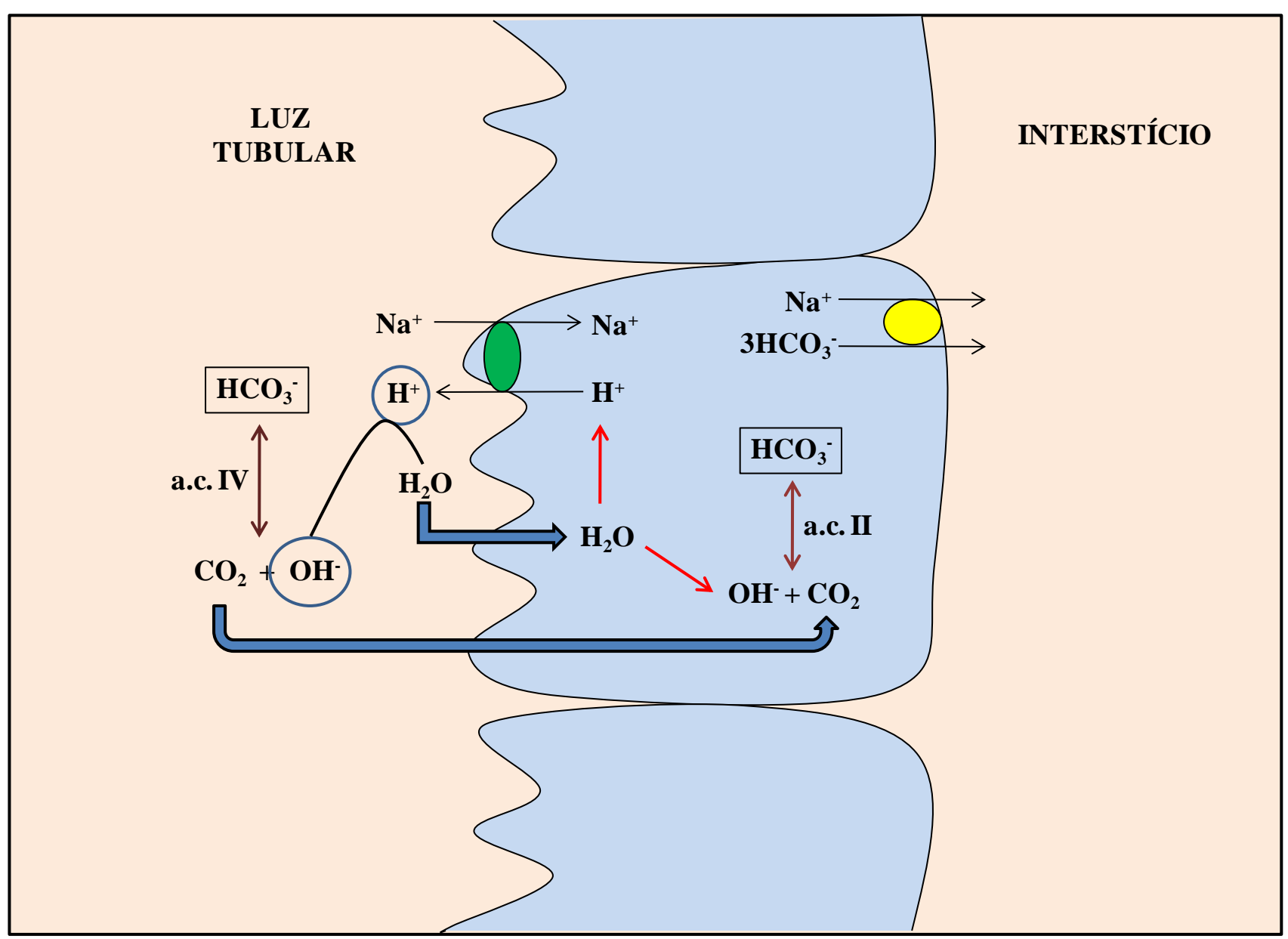

Figura 4- Esquema representativo da reabsorção de $\mathrm{HCO}_{3}{ }^{-}$em células de túbulos proximais. a.c.: anidrase carbônica.

Alterações na ingestão de $\mathrm{Na}^{+}$são geralmente compensadas por ajustes na excreção renal desse íon, de modo que o balanço seja novamente estabelecido. A saída de ácidos e bases do organismo também deve ser ajustada à entrada/geração dessas substâncias. Esses ajustes podem ocorrer por meio de ações hormonais e incluem modulação aguda e, muitas vezes, crônica das proteínas renais de transporte.

\subsubsection{REGULAÇÃO AGUDA DE NHE3}

A atividade de NHE3 é finamente regulada por diversos fatores. De forma aguda, a maioria dos hormônios que modulam a atividade de NHE3 está associada à atividade de proteínas cinases e suas vias de sinalização intracelular (MOE, 1999). A regulação de NHE3 é 
complexa, visto que vários agentes podem atuar simultaneamente. Estudos demonstraram que mudanças celulares, como na osmolaridade, ou fenômenos sistêmicos, como contração de volume ou alteração no estado ácido-base do organismo, entre outros fatores, podem alterar a atividade de NHE3 (AMEMIYA et al., 1995; FISHER et al., 2001; SOLEIMANI et al., 1994). Além disso, a função de NHE3 pode ser modulada por diversos hormônios, como insulina, paratormônio (PTH) e angiotensina II (Ang II) (COLLAZO et al., 2000; FUSTER et al., 2007; SACCOMANI; MITCHELL; NAVAR, 1990). Atenção especial será dada a Ang II na seção 1.1.3. Os fatores moduladores podem regular agudamente a atividade de NHE3 via fosforilação, mudança de sua localização celular (alteram o tráfego de NHE3) e/ou mudança das proteínas que interagem com o trocador.

\subsection{FOSFORILAÇÃO DE NHE3}

Alguns agentes reconhecidamente alteram a atividade de NHE3 via fosforilação de aminoácidos em sua cauda C-terminal. Agentes que aumentam os níveis de cAMP nas células, como o PTH, inibem o NHE3 via fosforilação das serinas 605 e 552 por PKA. A regulação da fosforilação nesses sítios provavelmente está associada com a distribuição de NHE3 nos compartimentos celulares (KOCINSKY et al., 2005; KURASHIMA et al., 1997; YANG et al., 2004; ZHAO et al., 1999). As isoformas 1 e 2 de NHERF (fatores reguladores de NHE) estão envolvidas com a inibição de NHE3 por PKA, pois ligam NHE3 à ezrina (que funciona como sítio de ancoragem da cinase) e aproximam a PKA do NHE3 (LAMPRECHT; WEINMAN; YUN, 1998). A fosforilação de NHE3 em resíduos de serina por PKC foi demonstrada em estudos in vitro, porém, apenas a fosforilação por si só não foi capaz de induzir mudanças na atividade do trocador. O mecanismo pelo qual a fosforilação de aminoácidos na cauda C-terminal de NHE3 altera sua atividade ainda não é bem conhecido, mas parece que a interação com proteínas acessórias é necessária para que a modulação se complete (WEINMAN; SHENOLIKAR, 1986; WIEDERKEHR; ZHAO; MOE, 1999).

\subsection{TRÁFEGO DE NHE3 E RELAÇÃO COM PROTEÍNAS ACESSÓRIAS}

O NHE3 se encontra em diferentes microdomínios celulares e o movimento do trocador entre uma região e outra é uma das maneiras de regular sua atividade. A inserção de 
vesículas contendo NHE3 aumenta o número de trocadores na membrana plasmática e, consequentemente, aumenta sua atividade. Por outro lado, a retirada de NHE3 da membrana e sua passagem para vesículas subapicais diminui sua atividade. Assim, em última análise, o balanço entre a endocitose e a exocitose de vesículas contendo NHE3 dita o seu nível de expressão apical (ALEXANDER; GRISTEIN, 2009).

Além disso, o NHE3 presente na membrana plasmática pode ser encontrado principalmente em dois microdomínios: na região microvilar - na borda em escova - região em que se associa à dipeptidil peptidase IV (DPPIV) e é funcional; e na região intermicrovilar - na base do microvilo - em que se encontra associado à megalina e é inativo (BIEMESDERFER; DEGRAY; ARONSON, 2001; GIRARDI et al., 2001). Estudos em fibroblastos transfectados com NHE3 demonstraram que apenas uma pequena porção do NHE3 total foi inserida na membrana plasmática, enquanto que a maior parte do NHE3 celular se encontrava em compartimentos endossomais de reciclagem (JANECKI et al., 2000). D’Souza e colaboradores demonstraram que o NHE3 presente na membrana dos endossomos é funcional e transporta $\mathrm{H}^{+}$citosólico para dentro da vesícula e $\mathrm{Na}^{+}$luminal para fora (D'SOUZA et al., 1998). A figura 5 mostra a distribuição de NHE3 em compartimentos endossomais.

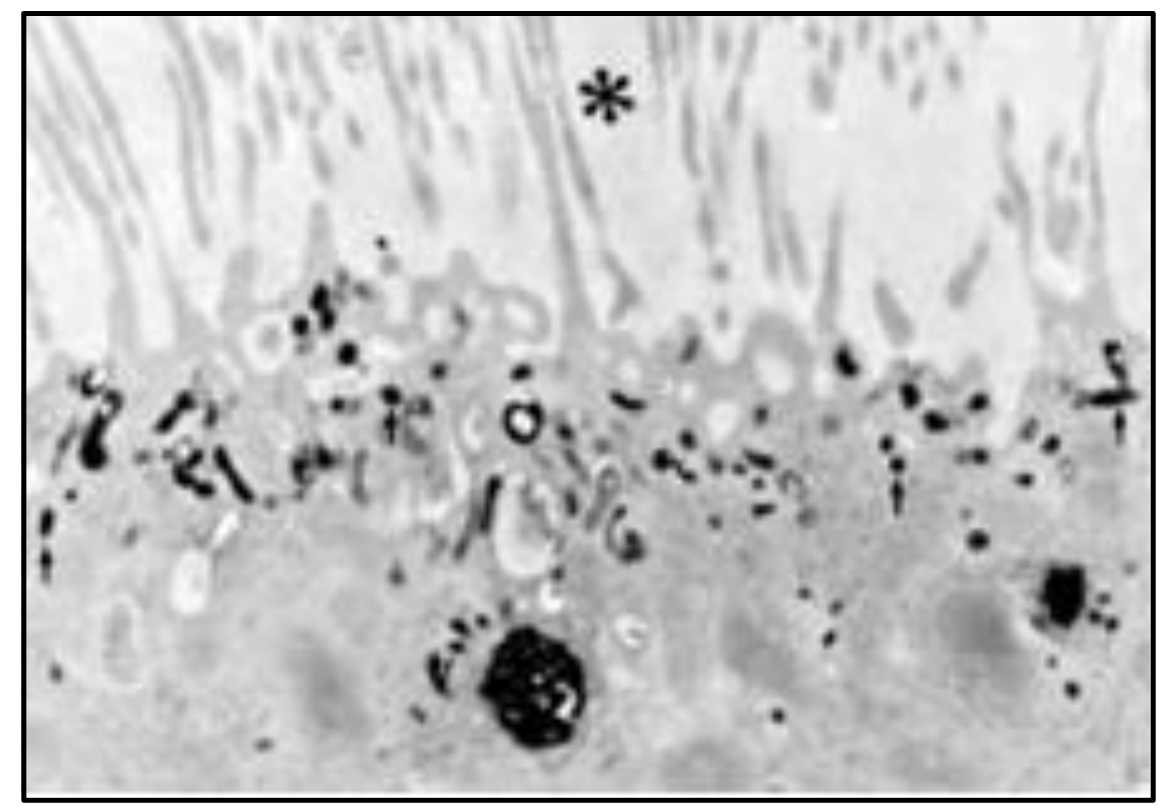

Figura 5- Micrografia eletrônica mostrando NHE3 marcado com HRP no compartimento endossomal. $O$ * representa o lúmen tubular.

FONTE: Biemesderfer et al. (2001).

A existência de NHE3 em diferentes microambientes celulares implica na interação de NHE3 com diferentes pools de proteínas. Esse transportador geralmente se encontra inserido 
em complexos protéicos que variam em constituição, dependendo da localização e do estado funcional da proteína. Li e colaboradores demonstraram, em íleos intactos, que NHE3 está presente simultaneamente em complexos protéicos de pesos moleculares variados em condições basais, o que sugere a interação de NHE3 com proteínas diversas, mesmo quando inserido na membrana plasmática (LI et al., 2004). As proteínas se ligam ao NHE3 em sua região C-terminal, que corresponde ao seu domínio regulatório. Várias dessas proteínas já foram identificadas, incluindo a família de fatores regulatórios de NHE (NHERF) e proteínas do grupo ERM (ezrina, radixina e moesina), entre outras (DONOWITZ; LI, 2007).

\section{Família NHERF}

Quatro isoformas de NHERF já foram descritas até o presente momento. Essas proteínas são modulares, formadas por 2 ou 4 módulos de domínios PDZ (constituídos, em média, por 90 aminoácidos), cuja principal característica é realizar interações entre proteínas. NHERF1 e 2 possuem dois domínios PDZ e um domínio ERM (responsável pela ligação com proteínas do citoesqueleto), enquanto que NHERF3 e 4 possuem 4 domínios PDZ (DONOWITZ et al., 2005). A representação esquemática dessas proteínas está demonstrada na figura 6.

\section{NHERF1 \\ (NHERF, EBP50) \\ PDZ1-PDD2-ERM \\ 358 aa \\ NHERF2 \\ (E3KARP, SIP-1, TKA-1) \\ PDZ1 1 PDZ2 ERM \\ 337 aa \\ NHERF3 PDZ1 PDZ2-PDZ3-PDZ4 519 aa \\ (PDZK1, CLAMP, CAP70, DIPHOR-1, NaPI-CaP1) \\ NHERF4 PDZ1-PDZ2-PDZ3-PDZ4 505 aa (IKEPP, DIPHOR-2, NaPI-CaP2)}

Figura 6- Representação esquemática dos domínios PDZ e ERM das isoformas de NHERF e número de aminoácidos. As siglas apresentadas entre parênteses correspondem às outras denominações dadas a essas proteínas.

FONTE: Donowitz et al. (2007).

Essas proteínas estão presentes simultaneamente em vários tipos celulares, inclusive no túbulo proximal de diversas espécies. NHERF1 é principalmente encontrado em membrana de borda em escova e colocaliza com NHE3, enquanto NHERF2 colocaliza pouco 
com NHE3 e se encontra principalmente na região intermicrovilar, exceto em túbulos proximais de ratos, que parece não expressar a isoforma 2 (WADE et al., 2001; WADE et al., 2003). Gisler e colaboradores demonstraram que NHERF3 colocaliza com NHERF1 e com NHE3 em células de túbulos proximais, ou seja, é expresso na região microvilar da membrana de borda em escova, enquanto NHERF4 se localiza principalmente no compartimento subapical (GISLER et al., 2001; SCOTT; THELIN; MILGRAM, 2002). A função dessas proteínas é foco de intensa investigação atualmente, pois apesar de já terem sido descritas funções específicas de algumas isoformas, parece haver também sobreposição funcional entre elas.

\section{Família ERM}

A família de proteínas ERM é formada por ezrina, radixina e moesina. Essas proteínas auxiliam na interação do citoesqueleto com a membrana plasmática e participam da transdução de sinal de algumas vias de sinalização (BRETSCHER et al., 2000). Dentre essas proteínas, a ezrina se liga direta e indiretamente ao NHE3. Essa proteína é altamente expressa na região apical microvilar de diversas células epiteliais, contribuindo para manutenção de sua polaridade e ligando proteínas específicas da membrana plasmática à actina do citoesqueleto (BERRYMAN; FRANCK; BRETSCHER, 1993).

Alexander e colaboradores demonstraram que a presença funcional do citoesqueleto de actina é importante para que NHE3 possa exibir sua atividade máxima (ALEXANDER et al., 2005). A ezrina parece fazer parte das proteínas que funcionam como ponte entre NHE3 e a actina do citoesqueleto, pois além de se ligar ao NHERF e à PKA, ela também interage com a actina por meio de seu domínio C-terminal (NIGGLI; ROSSY, 2008). A ligação direta entre NHE3 e ezrina parece estar relacionada com o tráfego de NHE3 para a membrana celular, tanto das proteínas recém-sintetizadas, quanto das recicladas (CHA et al., 2006). A figura 7 representa um esquema de NHE3 e algumas das proteínas que com ele interagem. 


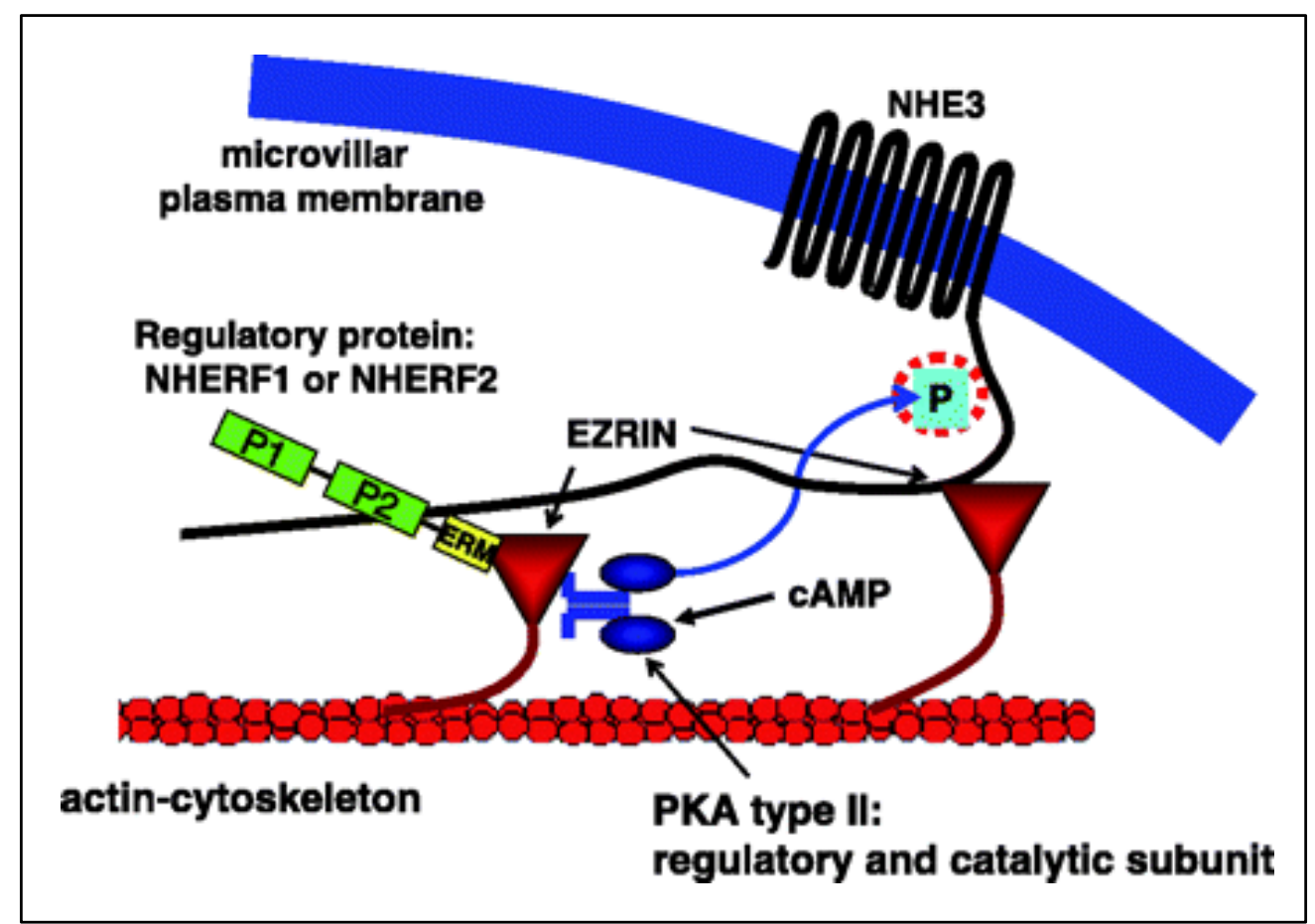

Figura 7- Esquema representativo de um complexo protéico envolvendo NHE3, NHERF1/2, ezrina, actina e PKA.

FONTE: Donowitz et al. (2007).

\section{Proteínas relacionadas com a sinalização que envolve o Cálcio}

Entre os diversos estímulos e segundos mensageiros que regulam a atividade de NHE3, o cálcio se apresenta na literatura como um personagem controverso, pois seus efeitos sobre o trocador variam de acordo com o tipo celular estudado (CHOI et al., 2004; CHU et al., 1996; KIM et al., 2002). O sistema de sinalização que envolve o $\mathrm{Ca}^{2+}$ opera em uma larga escala de tempo, contribuindo para a regulação de diferentes processos fisiológicos, desde microsegundos, quando age em uma fenda sináptica, até minutos ou horas, quando atua na regulação da transcrição gênica ou da proliferação celular (BERRIDGE; BOOTMAN; RODERICK, 2003). O maior estoque intracelular de $\mathrm{Ca}^{2+}$ se encontra no retículo endoplasmático e muitos estímulos extracelulares como hormônios, fatores de crescimento e neurotransmissores possuem a habilidade de fazê-lo fluir para o citoplasma. Muitos desses agentes atuam por meio da ativação da fosfolipase C (PLC), que forma inositol 1, 4, 5 trifosfato $\left(\mathrm{IP}_{3}\right)$ a partir de fosfatidilinositol 4, 5 bifosfato. $\mathrm{O} \mathrm{IP}_{3}$ formado liga-se aos seus receptores específicos presentes na membrana do retículo endoplasmático $\left(\mathrm{IP}_{3} \mathrm{R}\right)$ e libera parte do $\mathrm{Ca}^{2+}$ presente em seu interior.

Em 2003 foi identificada uma proteína que se liga ao receptor de $\mathrm{IP}_{3}$, chamada $I P_{3}$ receptor-binding protein released with $I P_{3}$ (IRBIT). Essa proteína inibe a ativação de $\mathrm{IP}_{3} \mathrm{R}$ e a 
liberação de $\mathrm{Ca}^{2+}$, pois compete com o $\mathrm{IP}_{3}$ em sua ligação com o receptor. He e colaboradores demonstraram que IRBIT se liga diretamente ao NHE3 e sua presença é necessária para que haja aumento da atividade do trocador quando a concentração de $\mathrm{Ca}^{2+}$ intracelular se eleva. $\mathrm{O}$ aumento de atividade observado pelos investigadores se deve ao aumento da inserção de vesículas contendo NHE3 na membrana plasmática. A interação entre NHE3 e IRBIT parece ocorrer na região entre os aminoácidos 591 e 696 da cauda C-terminal do trocador (HE; ZHANG; YUN, 2008).

Zachos e colaboradores demonstraram que a PLC $\gamma$ também se liga de forma direta ao NHE3, provavelmente entre os aminoácidos 586 e 605 de sua cauda C-terminal. A ligação com a PLC $\gamma$ parece ser fundamental para que a modulação de NHE3 dependente do aumento da concentração do $\mathrm{Ca}^{2+}$ citosólico seja realizada. Porém, de forma contrária ao que foi relatado por He e colaboradores, os resultados desses experimentos mostraram que a elevação do $\mathrm{Ca}^{2+}$ intracelular gerou inibição da atividade de NHE3. Nesse caso, foi descrito que a PLC $\gamma$ não modula o trocador por meio de sua atividade como lipase, mas sim funciona como região de ancoragem para outras proteínas que regulam a atividade do NHE3, como cinases ou fosfatases (ZACHOS et al., 2009).

Parece que o aumento da concentração do $\mathrm{Ca}^{2+}$ intracelular modula o NHE3 por duas vias distintas: ocorre uma regulação positiva quando NHE3 está ligado com IRBIT e uma regulação negativa quando NHE3 está ligado com NHERF2. IRBIT e NHERF2 são proteínas que possuem sítios sobrepostos de ligação no trocador, o que sugere a possibilidade de deslocamento entre elas em sua ligação com NHE3. Outra possibilidade seria a existência de dois pools de NHE3, um ligado a IRBIT e outro ligado ao NHEFR2, e a modulação do trocador seria determinada pela expressão relativa dessas proteínas acessórias (HE; ZHANG; YUN, 2008; KIM et al., 2002). He e colaboradores propuseram um modelo que representa a modulação de NHE3 envolvendo alterações nas proteínas que se ligam ao trocador em decorrência do aumento do $\mathrm{Ca}^{2+}$ citosólico. A representação esquemática desse modelo pode ser observada na figura 8 . 


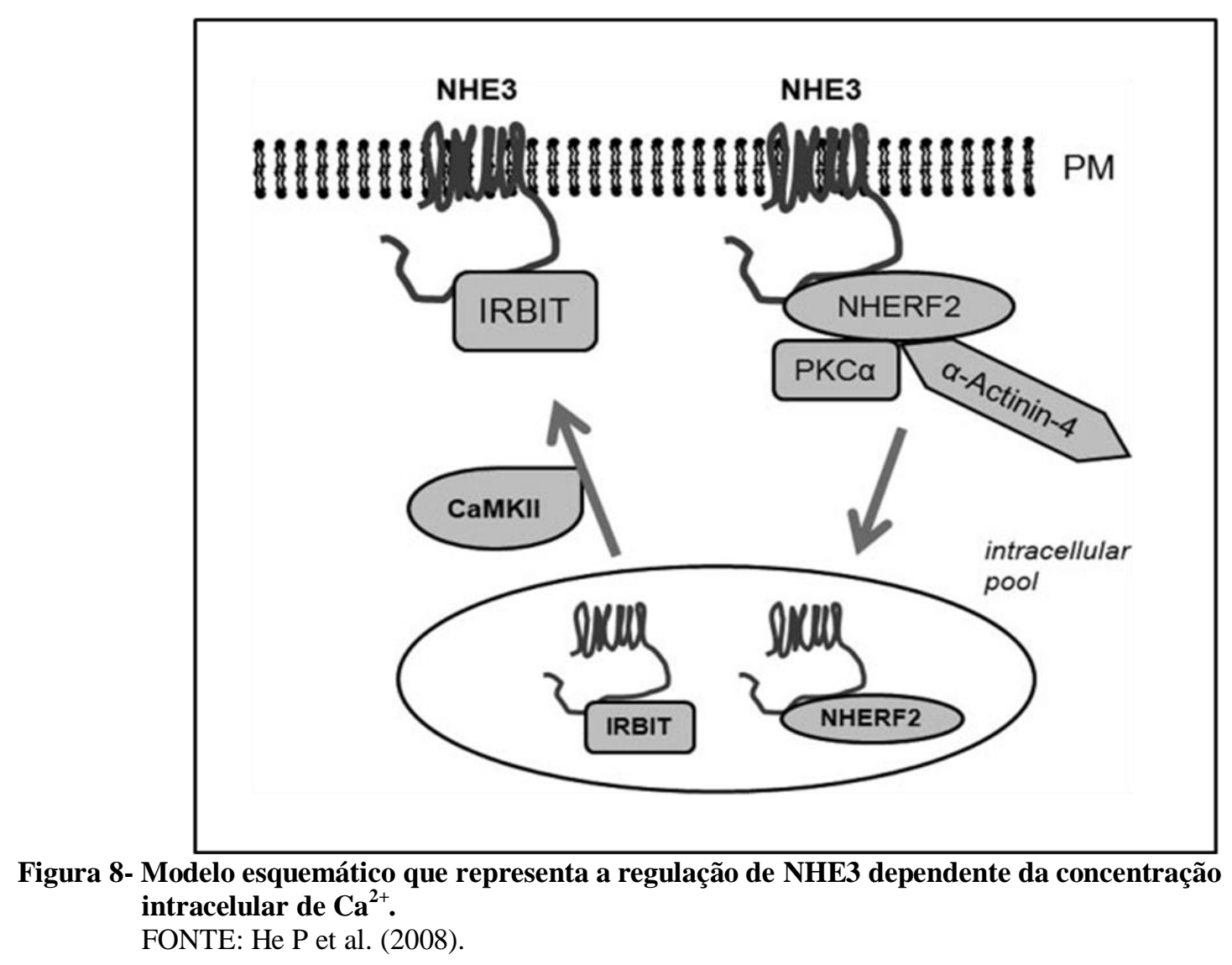

Foram citados apenas alguns grupos de proteínas que interagem direta ou indiretamente com NHE3, porém há muitas outras proteínas descritas que desempenham papel importante na modulação da atividade desse trocador. Os agrupamentos de proteínas formados próximos à membrana plasmática são complexos e se comportam de forma dinâmica, tornando indispensável o conhecimento das interações entre as proteínas para a compreensão do papel funcional de uma proteína específica. A ligação de NHE3 com um grupo ou outro de proteínas contribui para que sua atividade seja regulada de maneira específica.

\subsubsection{REGULAÇÃO CRÔNICA DE NHE3}

Situações em que o estímulo é prolongado podem provocar ativação do promotor do gene que codifica a proteína NHE3 e, consequentemente, gerar aumento da produção de seu RNAm (KIELA et al., 2001; MALAKOOTI et al., 2006). Para que qualquer gene seja transcrito é necessária a presença de uma sequência regulatória de DNA localizada imediatamente antes do sítio de início de transcrição, chamada de região promotora. É nessa região que se liga o complexo transcricional primário, que inclui a enzima RNA polimerase II 
e suas proteínas acessórias. A montagem e a estabilidade do complexo transcricional primário podem ser alteradas por interações com proteínas que modificam a estrutura da cromatina ou por fatores de transcrição (também chamados de elementos trans), que são proteínas que interagem com o DNA em sítios específicos (regiões também denominadas como elementos cis).

Os fatores de transcrição são classificados de acordo com a região da proteína envolvida no reconhecimento de sítios específicos do DNA. Essas proteínas não podem ser classificadas como estimulatórias ou inibitórias, pois elas desempenham seus papéis em conjunto com outras proteínas de forma dinâmica e, dependendo do conjunto de proteínas presentes naquela região de interação com o DNA, haverá estímulo ou inibição da taxa de transcrição de determinado gene. O sítio de início de transcrição de um gene é sempre denominado posição +1 , os pares de base anteriores a esse sítio são representados com sinal negativo (região promotora) e os pares de base que correspondem ao gene (exons e introns) são representados com sinal positivo.

\subsection{ESTUDO DA REGIÃO PROMOTORA DE NHE3}

Os primeiros estudos da região promotora de NHE3 de rato foram realizados por dois grupos independentes, ambos em 1996. A região promotora propriamente dita corresponde a aproximadamente $150 \mathrm{pb}$ anteriores ao sítio de início de transcrição e não apresenta os elementos TATA e CCAAT/enhancer-binding protein (C/EBP) boxes típicos, mas possui a sequência ATTAAA na posição -31 e três possíveis sítios de ligação para os fatores de transcrição Sp1 e Egr-1 (CANO, 1996; KANDASAMY; ORLOWSKI, 1996). Estudos realizados pelo grupo de Kiela, também utilizando promotor de rato, demonstraram em células de adenocarcinoma de colon humano (Caco-2) que elementos presentes no primeiro exon também podem atuar na regulação da transcrição gênica. Esses estudos demonstraram que o elemento GATA presente na posição +20 no primeiro exon é reconhecido pelo fator de transcrição GATA-5 e sua ligação, em conjunto com a ativação de outros fatores de transcrição, resulta em aumento da taxa de transcrição gênica (KIELA et al., 2003).

A região promotora do gene NHE3 humano foi mapeada por Malakooti e colaboradores em 2002. Alguns elementos cis estão presentes tanto no promotor de NHE3 de ratos quanto de humanos, como sítios consensuais para ligação de Egr-1 e Sp1, porém, também foram encontradas sequências consensuais para fatores de transcrição que são 
exclusivas de cada promotor, o que sugere a existência de diferentes estratégias no controle da expressão gênica nessas duas espécies (MALAKOOTI et al., 2002).

A região proximal do promotor de NHE3 de rato e os sítios consensuais para ligação de fatores de transcrição estão esquematizados na figura 9. Alguns dos fatores de transcrição apresentados na figura foram obtidos com o auxílio de um programa para análise de promotores, chamado MatInspector (Genomatix).

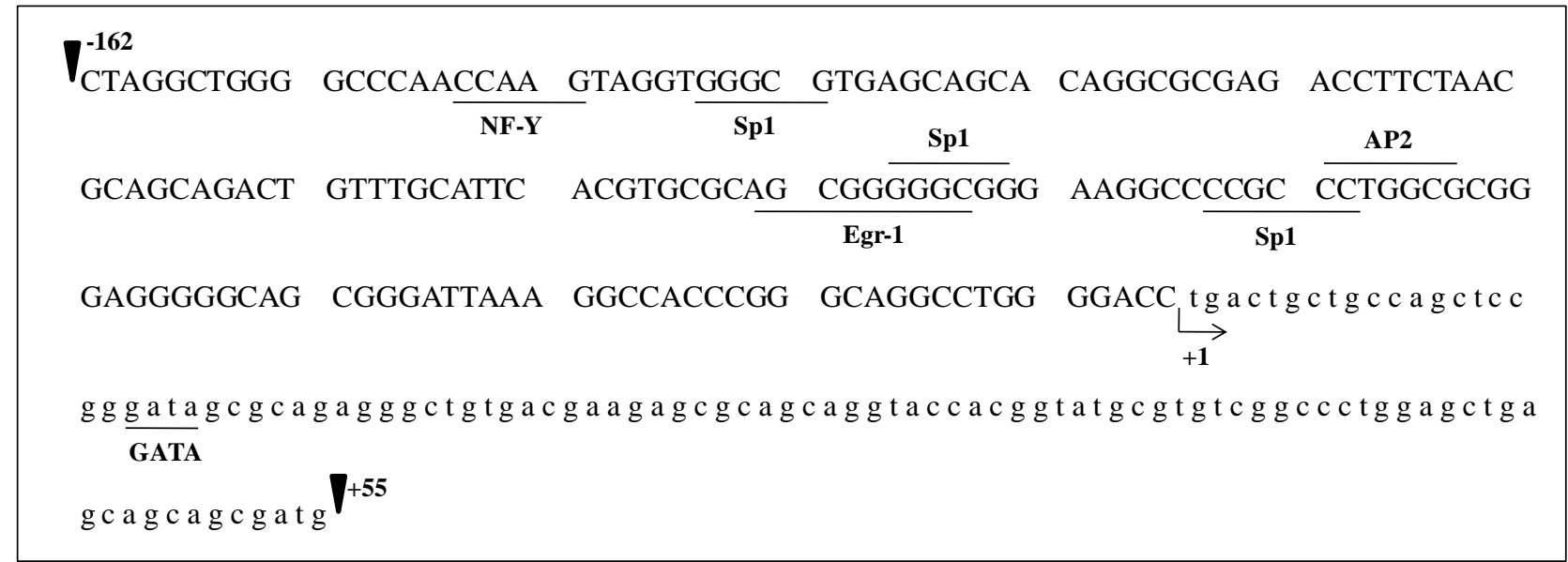

Figura 9- Representação esquemática de 162 nucleotídeos da região promotora (letras maiúsculas) e 55 nucleotídeos do primeiro exon (letras minúsculas) do gene NHE3 de rato. Os nucleotídeos destacados são sítios consensuais de ligação para fatores de transcrição.

Bezerra e colaboradores demonstraram que ocorre modulação transcricional de NHE3 quando células OKP são expostas ao PTH por longo período de tempo (BEZERRA et al., 2008). Outro estudo utilizando células Caco-2 mostrou que houve estímulo da atividade promotora de NHE3 após exposição prolongada a Ang II (MUSCH; LI; CHANG, 2009). A modulação aguda de NHE3 por Ang II foi extensivamente estudada por uma série de pesquisadores, porém, são poucos os dados disponíveis sobre a modulação crônica.

\subsubsection{Angiotensina II}

Ang II é o principal peptídeo vasoativo do sistema renina angiotensina aldosterona (SRAA) e desempenha papel fundamental no controle das funções cardiovascular e renal. Esse sistema é ativado, por exemplo, quando há redução do volume efetivo circulante, e desencadeia uma série de respostas que resultam no restabelecimento da volemia. A renina, produzida pelas células granulares renais (aparelho justaglomerular), atua como enzima na clivagem do angiotensinogênio plasmático em angiotensina I. Esta, por sua vez, é clivada em Ang II e essa reação é catalisada pela enzima conversora de angiotensina (ECA). 
A Ang II é um octapeptídeo que desempenha funções importantes no tecido renal, tais como participar da modulação da resistência arteriolar glomerular, do transporte de íons ao longo do néfron e da regulação do ciclo celular, induzindo proliferação ou hipertrofia, dependendo do tipo celular e dos fatores extracelulares envolvidos (TURBAN et al., 2006; WOLF; WENZEL, 2004). Além disso, ela age no córtex da glândula adrenal, estimulando a liberação de aldosterona, hormônio que também atua na modulação da reabsorção de $\mathrm{Na}^{+}$. Entre os efeitos da aldosterona estão a redução da retirada de canais do tipo ENaC da membrana, o aumento da taxa de transcrição do próprio $\mathrm{ENaC}$, de outras proteínas de transporte e de proteínas ligadas à produção de ATP, além de exercer outras funções em órgãos-alvo distintos.

A maioria das ações biológicas da Ang II é desencadeada após sua ligação com receptores do tipo AT1 (AT1R), apesar do hormônio se ligar, também com alta afinidade, em receptores do tipo AT2 (AT2R). Os subtipos de receptores puderam ser caracterizados devido ao desenvolvimento de antagonistas seletivos, como losartan no caso de AT1R e PD123319, no caso de AT2R. Em roedores, há duas isoformas distintas de AT1R: AT1a e AT1b e a maioria dos efeitos biológicos da Ang II nesses animais ocorre via estímulo de AT1a (BADER; GANTEN, 2008; HAULICA; BILD; SERBAN, 2005; TIMMERMANS et al., 1993). A figura 10 mostra um esquema simplificado do SRAA clássico. 


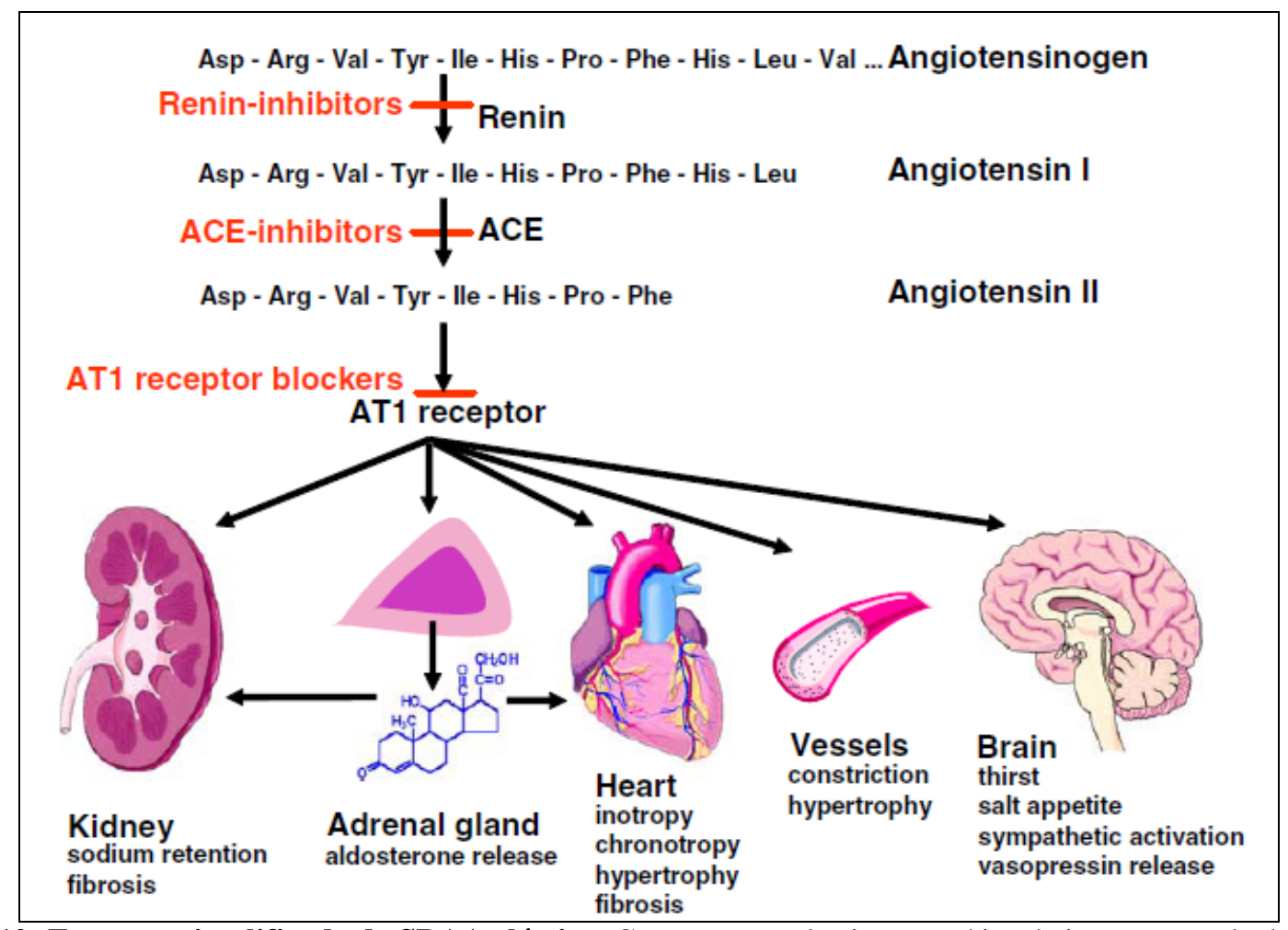

Figura 10- Esquema simplificado do SRAA clássico. Componentes do sistema, sítios de intervenção de drogas clinicamente aprovadas (em vermelho) e os principais efeitos nos diferentes órgãos-alvo. FONTE: Bader et al. (2008).

AT1R é um receptor que possui 7 alças transmembrana e está acoplado à proteína G. Sua ligação com a Ang II pode desencadear cinco vias clássicas de transdução de sinal: ativação das fosfolipases $\mathrm{A}_{2}, \mathrm{C}$ e $\mathrm{D}$, ativação de canais para $\mathrm{Ca}^{2+}$ do tipo $\mathrm{L}$ e inibição da adenilato ciclase (DINH et al., 2001). Há vários estudos que demonstram a ativação de vias de sinalização independentes de proteína G após ligação da Ang II com o receptor AT1. Foi demonstrada a participação da Src cinase e do fator de crescimento epidermal (EGFR) na ativação da via de sinalização da proteína cinase ativada por mitógeno (MAPK) após estímulo por Ang II. Estudos também mostraram a ativação da via janus kinase (JAK)/signal transducers and actiavators of transcription (STAT) após ligação de Ang II com AT1R. As cascatas de sinalização ativadas por Ang II podem resultar no estímulo, recrutamento ou inibição de fatores de transcrição e contribuem, portanto, para a modulação da transcrição de genes-alvo (BLUME; HERDEGEN; UNGER, 1999; EGUCHI et al., 1998; SCHIEFFER et al., 1996). A figura 11 representa um esquema de algumas das vias de sinalização que podem ser ativadas por Ang II. 


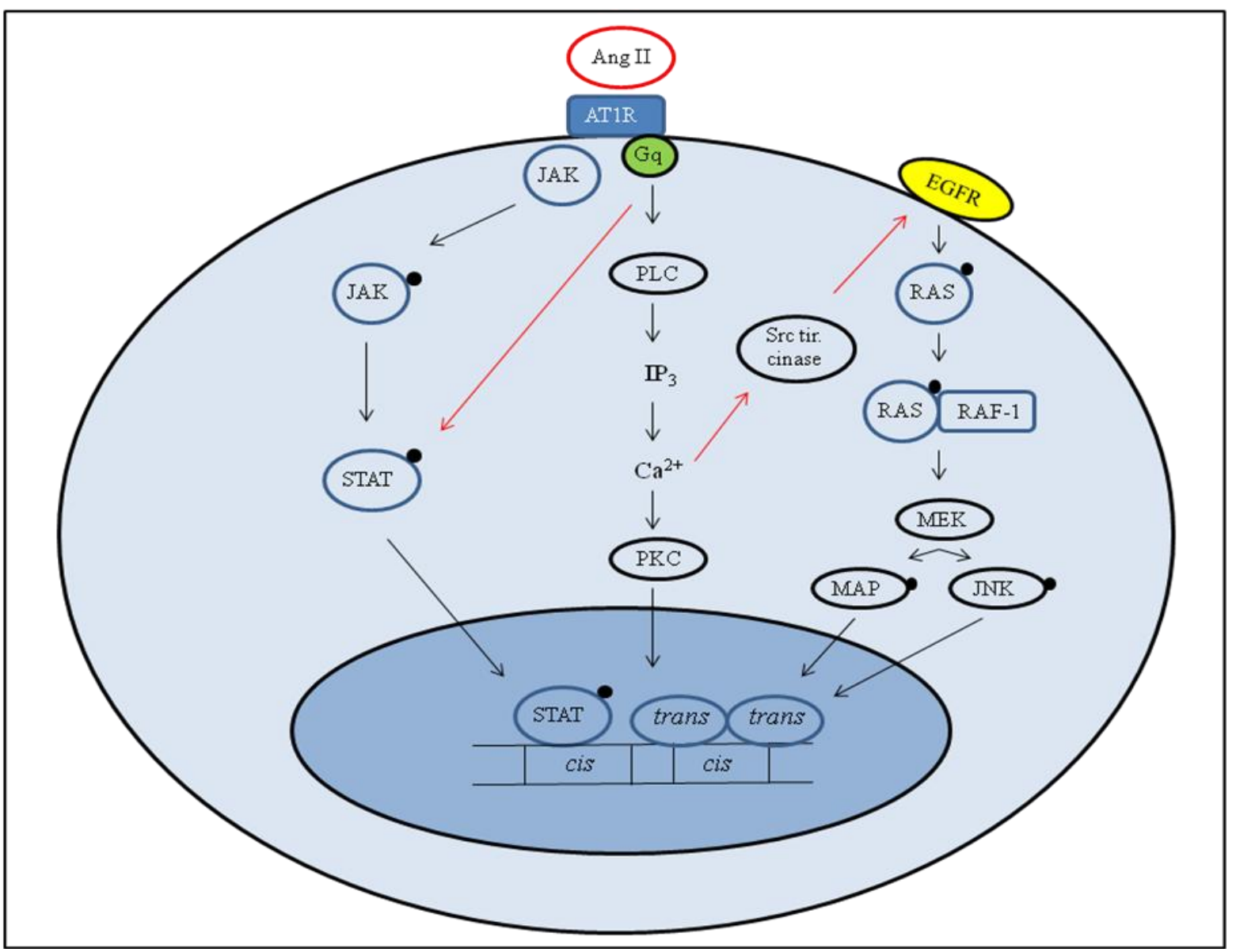

Figura 11- Algumas das vias de sinalização ativadas pela ligação de Ang II em AT1R. As setas vermelhas representam possíveis pontos de transativação entre as vias. • representa o grupo fosfato. FONTE: modificado de Blume et al. (1999).

O sistema renina angiotensina é muito mais complexo do que a visão clássica apresenta. Há vias alternativas da formação de seus componentes intermediários e existem outros peptídeos que possuem papel fisiológico relevante. Enzimas como tonina, catepsinas e calicreínas podem gerar Ang II de forma direta ou indireta a partir de angiotensinogênio e a enzima quimase parece ser importante para a geração de Ang II em tecido cardiovascular (BELOVA, 2000; NISHIMOTO et al., 2001). Alguns dos peptídeos que também possuem papel fisiológico relevante são a angiotensina III (Ang III), que é formada a partir de Ang II por ação da enzima aminopeptidase A e exerce efeitos similares aos da Ang II; e a angiotensina 1-7 (Ang 1-7), que é gerada por ação da enzima conversora de angiotensina 2 (ECA 2) e exerce efeitos antagônicos aos da Ang II (FYHRQUIST; SAIJONMAA, 2008). Um esquema resumido da via clássica e de alguns dos novos personagens que participam desse sistema está representado na figura 12. 


\section{Angiotensinogen}

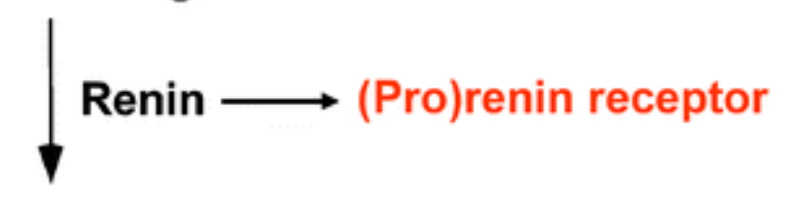

Angiotensin(1-9)

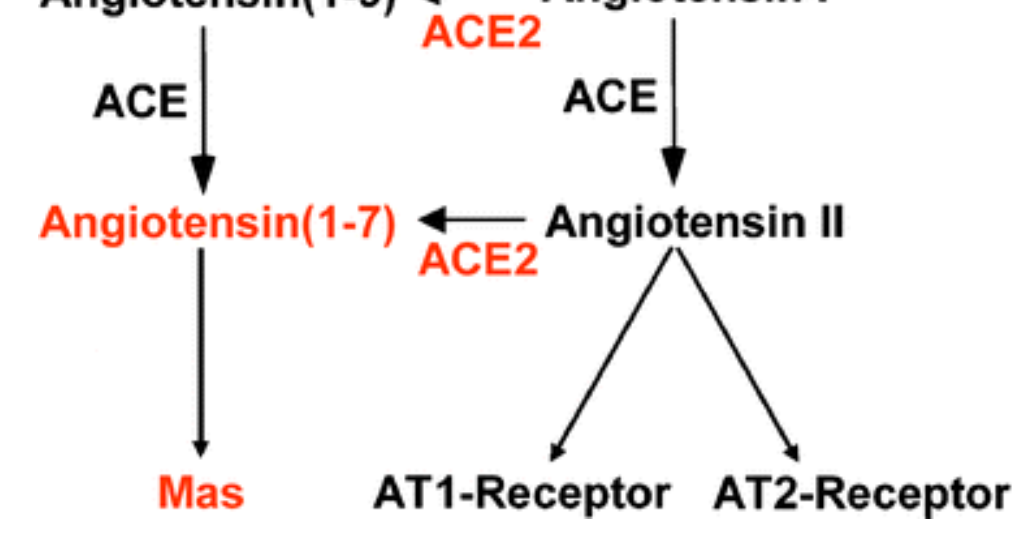

Figura 12- Esquema representativo da via clássica e algumas das vias alternativas de formação dos componentes do SRA.

FONTE: Bader et al. (2008).

Além do sistema renina-angiotensina (SRA) sistêmico há também um SRA local em diversos tecidos. A maioria dos componentes necessários para a geração de Ang II local já foram identificados no cérebro, tecido cardíaco e nos rins, órgãos importantes para o controle da função cardiovascular (BADER; GANTEN, 2008). Nos rins, a geração de Ang II é tão eficiente que esse hormônio possui concentrações muito mais altas no interior desse órgão do que na circulação sanguínea, o que não pode ser explicado apenas com base no equilíbrio entre a circulação renal e a sistêmica. Além disso, a concentração de Ang II renal parece ser regulada de maneira independente da sistêmica (BADER; GANTEN, 2008; CAMPBELL et al., 1991; KOBORI et al., 2007a). Há também estudos que sugerem a produção de Ang II intracelular em células que, em certas condições, expressam os componentes necessários para que essa geração ocorra (KUMAR; SINGH; BAKER, 2007). Assim, o SRA pode ser considerado um sistema endócrino, parácrino e até mesmo intrácrino que, de maneira complexa, regula a atividade e expressão de diversas proteínas.

\subsubsection{Angiotensina II e NHE3}

A regulação aguda de NHE3 por Ang II é caracterizada por um efeito bimodal, observado de maneira independente por investigadores de vários laboratórios. Baixas 
concentrações do hormônio estimulam a atividade do trocador e altas concentrações a inibem (HARRIS; YOUNG, 1977; SCHUSTER; KOKKO; JACOBSON, 1984; WANG; CHAN, 1990). Alguns estudos demonstraram que os efeitos agudos da Ang II na atividade do trocador ocorrem via AT1R em túbulos proximais in vivo, em células OKP (uma sublinhagem de células OK, opossum kidney cell, extraídas da espécie Didelphis virginiana) e MKCC, uma linhagem celular de túbulos corticais de camundongos (CANO et al., 1994; DU et al., 2003; XIE et al., 1990). A inibição da adenilato ciclase, a consequente queda da concentração de cAMP e diminuição da ativação de PKA é um dos mecanismos pelo qual a Ang II estimula de forma aguda a atividade de NHE3, pois ocorre queda da fosforilação em sua cauda Cterminal, o que resulta em maior permanência da proteína na membrana plasmática. Entretanto, esse mecanismo não foi observado em células OKP, nas quais o efeito da Ang II na atividade do trocador parece ser independente da concentração de cAMP (CANO et al., 1994; LIU; COGAN, 1989). Além da queda da fosforilação em sua cauda C-terminal, a Ang II também estimula a inserção de vesículas contendo NHE3 na membrana apical, contribuindo para o aumento de sua atividade. Esse mecanismo parece ser dependente de PI3-cinase (PI3K) e da integridade dos filamentos de actina do citoesqueleto (DU et al., 2003). Recentemente foi proposto que o efeito da Ang II na translocação de vesículas contendo NHE3 para a membrana plasmática está envolvido com a calmodulina cinase II (CaMKII) e a proteína IRBIT. He e colaboradores sugeriram que a ativação de AT1R leva ao aumento da concentração intracelular de $\mathrm{Ca}^{2+}$ e subsequente ativação de CaMKII, que fosforila IRBIT, aumenta a sua interação com NHE3 e promove sua migração para a membrana plasmática (HE; KLEIN; YUN, 2010).

A inibição aguda da atividade de NHE3 provocada por exposição a altas concentrações de Ang II parece ocorrer via fosfolipase $\mathrm{A}_{2}$ e metabólitos derivados do ácido araquidônico, como citocromo P450 (HOUILLIER et al., 1996). Porém, esse efeito talvez não tenha relevância fisiológica, pois as concentrações de Ang II necessárias para que esse efeito inibitório seja observado são muito altas (da ordem de $10^{-8}$ a $10^{-6} \mathrm{M}$ ) e não se sabe se há possibilidade dessas concentrações serem alcançadas em alguma situação in vivo.

Os efeitos crônicos da Ang II na atividade e expressão de NHE3 são mais escassos na literatura. Xu e colaboradores descreveram estímulo da atividade e expressão de NHE3 após 16 horas de tratamento com Ang II na concentração de $10^{-7} \mathrm{M}$ (XU et al., 2006). Estudos utilizando modelos animais mostraram que: 1) não há aumento da quantidade total de NHE3 após 3 dias de infusão de Ang II; 2) ratos infundidos com Ang II por 7 dias apresentaram aumento da quantidade e atividade de NHE3 em vesículas de membrana de borda em escova 
(DIXIT et al., 2004; TURBAN et al., 2006). Há poucos estudos sobre a ativação transcricional e região promotora de NHE3 modulada por Ang II (MUSCH; LI; CHANG, 2009; XU et al., 2006). 


\section{CONCLUSÕES}

O tratamento prolongado com baixa concentração de Ang II promoveu aumento na atividade de NHE3 em células OKP. Altas concentrações desse hormônio não desencadearam respostas inibitórias na atividade do transportador, o que sugere que o efeito bimodal da Ang II sobre a atividade de NHE3, característico nos tratamentos agudos, não pode ser observado no tratamento crônico.

O aumento da atividade de NHE3 durante o tratamento prolongado com Ang II foi consequência, pelo menos em parte, do aumento da expressão da proteína NHE3. O tratamento crônico com baixa concentração de Ang II também promoveu aumento da quantidade do RNAm de NHE3, provavelmente devido ao aumento na taxa de transcrição gênica, sem interferir no tempo de $1 / 2$ vida do RNAm. A ativação da transcrição gênica foi observada pelo estímulo da região promotora proximal do gene NHE3. Além disso, foi demonstrado que as vias de sinalização intracelulares que envolvem o citocromo P450, a PKA, a PI3-K e MAPK estão envolvidas no estímulo da atividade promotora do fragmento 65/+31 do promotor do gene NHE3 gerado por Ang II. As vias que envolvem a PLC e as proteínas JAK/STAT não parecem ser ativadas nessas condições. Os dados do presente trabalho não possibilitam concluir se a presença prolongada da Ang II ativou individualmente todas as vias envolvidas ou se houve transativação em um ou mais pontos das vias estudadas. Porém, é possível afirmar que a presença crônica de Ang II desencadeou complexas alterações intracelulares que resultaram em um efeito estimulatório sobre a atividade de NHE3 e sobre a atividade promotora de transcrição da região flanqueadora 5' proximal do gene que codifica essa proteína. Os resultados obtidos sugerem ainda que a modulação transcricional de NHE3 por Ang II parece ser dependente da integridade do sítio no DNA para ligação do fator de transcrição Sp1/Egr-1.

Todas as respostas desencadeadas pela Ang II observadas no presente trabalho foram decorrentes de sua ligação com receptores do tipo AT1, o que demonstra o envolvimento desse receptor na regulação da reabsorção de $\mathrm{Na}^{+}$e extrusão de $\mathrm{H}^{+}$mediada por presença crônica de Ang II.

Esses dados em conjunto nos permitem concluir que a exposição prolongada a Ang II gerou respostas celulares e moleculares que, em conjunto, resultaram no aumento da expressão e atividade de NHE3. A capacidade da Ang II de modular a expressão gênica em 
situações de estímulo crônico pode representar um importante papel na regulação da reabsorção de $\mathrm{Na}^{+}$e água em túbulos proximais. 


\section{REFERÊECIAS ${ }^{2}$}

ALEXANDER, R. T.; FURUYA, W.; SZASZI, K.; ORLOWSKI, J.; GRINSTEIN, S. Rho GTPases dictate the mobility of the $\mathrm{Na} / \mathrm{H}$ exchanger NHE3 in epithelia: role in apical retention and targeting. Proc. Natl. Acad. Sci. U.S.A, v. 102, p. 12253-12258, 2005.

ALEXANDER, R. T.; GRINSTEIN, S. Na+/H+ exchangers and the regulation of volume. Acta Physiol. (Oxf.), v. 187, p. 159-167, 2006.

ALEXANDER, R. T.; GRINSTEIN, S. Tethering, recycling and activation of the epithelial sodium-proton exchanger, NHE3. J. Exp. Biol., v. 212, p. 1630-1637, 2009.

AMEMIYA, M.; YAMAJI, Y.; CANO, A.; MOE, O. W.; ALPERN, R. J. Acid incubation increases NHE-3 mRNA abundance in OKP cells. Am. J. Physiol., v. 269, C126-C133 1995.

AMIN, M. R.; MALAKOOTI, J.; SANDOVAL, R.; DUDEJA, P. K.; RAMASWAMY, K. IFNgamma and TNF-alpha regulate human NHE3 gene expression by modulating the Sp family transcription factors in human intestinal epithelial cell line C2BBe1. Am. J. Physiol. Cell Physiol., v. 291, C887-C896, 2006.

ARGETSINGER, L. S.; STUCKEY, J. A.; ROBERTSON, S. A.; KOLEVA, R. I.; CLINE, J. M.; MARTO, J. A.; MYERS, M. G., JR.; CARTER-SU, C. Tyrosines 868, 966, and 972 in the kinase domain of JAK2 are autophosphorylated and required for maximal JAK2 kinase activity. Mol. Endocrinol., v. 24, p. 1062-1076, 2010.

ARONSON, P. S.; NEE, J.; SUHM, M. A. Modifier role of internal H+ in activating the Na+-H+ exchanger in renal microvillus membrane vesicles. Nature, v. 299, p. 161-163, 1982.

ATLAS, S. A. The renin-angiotensin aldosterone system: pathophysiological role and pharmacologic inhibition. J. Manag. Care Pharm., v. 13, p. 9-20, 2007.

\footnotetext{
${ }^{2}$ De acordo com: ASSOCIAÇÃO BRASILEIRA DE NORMAS TÉCNICAS. NBR 6023: Informação e documentação: referências: elaboração. Rio de Janeiro, 2002.
} 
BADER, M.; GANTEN, D. Update on tissue renin-angiotensin systems. J. Mol. Med., v. 86, p. 615-621, 2008.

BAUM, M.; CANO, A.; ALPERN, R. J. Glucocorticoids stimulate Na+/H+ antiporter in OKP cells. Am. J. Physiol., v. 264, p. F1027-F1031, 1993.

BCECF, ([2010]). Disponível em http://probes.invitrogen.com/media/pis/mp01150.pdf.

BELOVA, L. A. Angiotensin II-generating enzymes. Biochemistry (Mosc.), v. 65, p. 1337-1345, 2000.

BERRIDGE, M. J.; BOOTMAN, M. D.; RODERICK, H. L. Calcium signalling: dynamics, homeostasis and remodelling. Nat. Rev. Mol. Cell Biol., v. 4, p. 517-529, 2003.

BERRYMAN, M.; FRANCK, Z.; BRETSCHER, A. Ezrin is concentrated in the apical microvilli of a wide variety of epithelial cells whereas moesin is found primarily in endothelial cells. J. Cell Sci., v. 105, pt 4, p. 1025-1043, 1993.

BEZERRA, C. N.; GIRARDI, A. C.; CARRARO-LACROIX, L. R.; REBOUCAS, N. A. Mechanisms underlying the long-term regulation of NHE3 by parathyroid hormone. Am. J. Physiol. Renal Physiol., v. 294, p. F1232-F1237, 2008.

BHAT, G. J.; THEKKUMKARA, T. J.; THOMAS, W. G.; CONRAD, K. M.; BAKER, K. M. Activation of the STAT pathway by angiotensin II in T3CHO/AT1A cells. Cross-talk between angiotensin II and interleukin-6 nuclear signaling. J.Biol.Chem., v. 270, p. 19059-19065, 1995.

BIEMESDERFER, D.; DEGRAY, B.; ARONSON, P. S. Active (9.6 s) and inactive (21 s) oligomers of NHE3 in microdomains of the renal brush border. J. Biol. Chem., v. 276, p. 1016110167, 2001.

BLUME, A.; HERDEGEN, T.; UNGER, T. Angiotensin peptides and inducible transcription factors. J. Mol. Med., v. 77, p. 339-357, 1999. 
BORON, W. F.; DE, W. P. Intracellular pH transients in squid giant axons caused by $\mathrm{CO} 2, \mathrm{NH} 3$, and metabolic inhibitors. J. Gen. Physiol., v. 67, p. 91-112, 1976.

BRAGA, M. F.; LEITER, L. A. Role of renin-angiotensin system blockade in patients with diabetes mellitus. Am. J. Cardiol., v. 104, p. 835-839, 2009.

BRETSCHER, A.; CHAMBERS, D.; NGUYEN, R.; RECZEK, D. ERM-Merlin and EBP50 protein families in plasma membrane organization and function. Annu. Rev. Cell Dev. Biol., v. 16, p. 113-143, 2000.

BRETT, C. L.; DONOWITZ, M.; RAO, R. Evolutionary origins of eukaryotic sodium/proton exchangers. Am. J. Physiol. Cell Physiol., v. 288, p. C223-C239, 2005.

CAMPBElL, D. J.; LAWRENCE, A. C.; TOWRIE, A.; KLADIS, A.; VALENTIJN, A. J. Differential regulation of angiotensin peptide levels in plasma and kidney of the rat. Hypertension, v. 18, p. 763-773, 1991.

CANO, A. Characterization of the rat NHE3 promoter. Am. J. Physiol., v. 271, p. F629-F636 1996.

CANO, A.; MILlER, R. T.; ALPERN, R. J.; PREISIG, P. A. Angiotensin II stimulation of Na-H antiporter activity is cAMP independent in OKP cells. Am. J. Physiol., v. 266, p. C1603-C1608 1994.

CANO, A.; PREISIG, P.; ALPERN, R. J. Cyclic adenosine monophosphate acutely inhibits and chronically stimulates $\mathrm{Na} / \mathrm{H}$ antiporter in OKP cells. J. Clin. Invest., v. 92, p. 1632-1638, 1993.

CHA, B.; TSE, M.; YUN, C.; KOVBASNJUK, O.; MOHAN, S.; HUBBARD, A.; ARPIN, M.; DONOWITZ, M. The NHE3 juxtamembrane cytoplasmic domain directly binds ezrin: dual role in NHE3 trafficking and mobility in the brush border. Mol. Biol. Cell, v. 17, p. 2661-2673, 2006. 
CHEN, J. K.; CAPDEVILA, J.; HARRIS, R. C. Overexpression of C-terminal Src kinase blocks 14, 15-epoxyeicosatrienoic acid-induced tyrosine phosphorylation and mitogenesis. J. Biol. Chem., v. 275, p. 13789-13792, 2000a.

CHEN, R.; MUKHIN, Y. V.; GARNOVSKAYA, M. N.; THIELEN, T. E.; IIJIMA, Y.; HUANG, C.; RAYMOND, J. R.; ULLIAN, M. E.; PAUL, R. V. A functional angiotensin II receptor-GFP fusion protein: evidence for agonist-dependent nuclear translocation. Am. J. Physiol. Renal Physiol., v. 279, p. F440-F448 2000b.

CHOI, J. W.; LEE-KWON, W.; JEON, E. S.; KANG, Y. J.; KAWANO, K.; KIM, H. S.; SUH, P. G.; DONOWITZ, M.; KIM, J. H. Lysophosphatidic acid induces exocytic trafficking of $\mathrm{Na}(+) / \mathrm{H}(+)$ exchanger 3 by E3KARP-dependent activation of phospholipase C. Biochim. Biophys. Acta, v. 1683, p. 59-68, 2004.

CHU, T. S.; PENG, Y.; CANO, A.; YANAGISAWA, M.; ALPERN, R. J. Endothelin(B) receptor activates NHE-3 by a Ca2+-dependent pathway in OKP cells. J. Clin. Invest., v. 97, p. 1454$1462,1996$.

CLYNE, C. D.; ZHANG, Y.; SLUTSKER, L.; MATHIS, J. M.; WHITE, P. C.; RAINEY, W. E. Angiotensin II and potassium regulate human CYP11B2 transcription through common ciselements. Mol. Endocrinol., v. 11, p. 638-649, 1997.

COLE, J. A.; FORTE, L. R.; KRAUSE, W. J.; THORNE, P. K. Clonal sublines that are morphologically and functionally distinct from parental OK cells. Am. J. Physiol., v. 256, p. F672-F679 1989.

COLLAZO, R.; FAN, L.; HU, M. C.; ZHAO, H.; WIEDERKEHR, M. R.; MOE, O. W. Acute regulation of $\mathrm{Na}+\mathrm{H}+$ exchanger NHE3 by parathyroid hormone via NHE3 phosphorylation and dynamin-dependent endocytosis. J. Biol. Chem., v. 275, p. 31601-31608, 2000.

COOK, J. L.; MILLS, S. J.; NAQUIN, R.; ALAM, J.; RE, R. N. Nuclear accumulation of the AT1 receptor in a rat vascular smooth muscle cell line: effects upon signal transduction and cellular proliferation. J. Mol.Cell Cardiol., v. 40, p. 696-707, 2006. 
COOK, J. L.; MILLS, S. J.; NAQUIN, R. T.; ALAM, J.; RE, R. N. Cleavage of the angiotensin II type 1 receptor and nuclear accumulation of the cytoplasmic carboxy-terminal fragment. Am. J. Physiol. Cell Physiol., v. 292, p. C1313-C1322 2007.

CUADRADO, A.; NEBREDA, A. R. Mechanisms and functions of p38 MAPK signalling. Biochem. J., v. 429, p. 403-417, 2010.

D'SOUZA, S.; GARCIA-CABADO, A.; YU, F.; TETER, K.; LUKACS, G.; SKORECKI, K.; MOORE, H. P.; ORLOWSKI, J.; GRINSTEIN, S. The epithelial sodium-hydrogen antiporter $\mathrm{Na}+\mathrm{H}+$ exchanger 3 accumulates and is functional in recycling endosomes. J. Biol. Chem., v. 273, p. 2035-2043, 1998.

DINH, D. T.; FRAUMAN, A. G.; JOHNSTON, C. I.; FABIANI, M. E. Angiotensin receptors: distribution, signalling and function. Clin. Sci. (Lond), v. 100, p. 481-492, 2001.

DIXIT, M. P.; XU, L.; XU, H.; BAI, L.; COLLINS, J. F.; GHISHAN, F. K. Effect of angiotensinII on renal Na+/H+ exchanger-NHE3 and NHE2. Biochim. Biophys. Acta, v. 1664, p. 38-44, 2004.

DONG, J.; RAMACHANDIRAN, S.; TIKOO, K.; JIA, Z.; LAU, S. S.; MONKS, T. J. EGFRindependent activation of p38 MAPK and EGFR-dependent activation of ERK1/2 are required for ROS-induced renal cell death. Am. J. Physiol. Renal Physiol., v. 287, p. F1049-F1058 2004.

DONOWITZ, M.; CHA, B.; ZACHOS, N. C.; BRETT, C. L.; SHARMA, A.; TSE, C. M.; LI, X. NHERF family and NHE3 regulation. J. Physiol., v. 567, p. 3-11, 2005.

DONOWITZ, M.; LI, X. Regulatory binding partners and complexes of NHE3. Physiol. Rev., v. 87, p. 825-872, 2007.

DU, C. D.; CHALUMEAU, C.; DEFONTAINE, N.; KLEIN, C.; KELLERMANN, O.; PAILLARD, M.; POGGIOLI, J. Angiotensin II stimulates NHE3 activity by exocytic insertion of the transporter: role of PI 3-kinase. Kidney Int., v. 64, p. 939-949, 2003. 
DZAU, V. J.; LOPEZ-ILASACA, M. Searching for transcriptional regulators of Ang II-induced vascular pathology. J. Clin. Invest., v. 115, p. 2319-2322, 2005.

ECKERT, D.; BUHL, S.; WEBER, S.; JAGER, R.; SCHORLE, H. The AP-2 family of transcription factors. Genome Biol., v. 6, 246-253, 2005.

EGUCHI, S.; NUMAGUCHI, K.; IWASAKI, H.; MATSUMOTO, T.; YAMAKAWA, T.; UTSUNOMIYA, H.; MOTLEY, E. D.; KAWAKATSU, H.; OWADA, K. M.; HIRATA, Y.; MARUMO, F.; INAGAMI, T. Calcium-dependent epidermal growth factor receptor transactivation mediates the angiotensin II-induced mitogen-activated protein kinase activation in vascular smooth muscle cells. J. Biol. Chem., v. 273, p. 8890-8896, 1998.

FISHER, K. A.; LEE, S. H.; WALKER, J.; DILETO-FANG, C.; GINSBERG, L.; STAPLETON, S. R. Regulation of proximal tubule sodium/hydrogen antiporter with chronic volume contraction. Am. J. Physiol. Renal Physiol., v. 280, p. F922-F926 2001.

FUSTER, D. G.; BOBULESCU, I. A.; ZHANG, J.; WADE, J.; MOE, O. W. Characterization of the regulation of renal $\mathrm{Na}+\mathrm{H}+$ exchanger NHE3 by insulin. Am. J. Physiol. Renal Physiol., v. 292, p. F577-F585 2007.

FYHRQUIST, F.; SAIJONMAA, O. Renin-angiotensin system revisited. J. Intern. Med., v. 264, p. 224-236, 2008.

GIRARDI, A. C.; DEGRAY, B. C.; NAGY, T.; BIEMESDERFER, D.; ARONSON, P. S. Association of $\mathrm{Na}(+)-\mathrm{H}(+)$ exchanger isoform NHE3 and dipeptidyl peptidase IV in the renal proximal tubule. J. Biol. Chem., v. 276, p. 46671-46677, 2001.

GISLER, S. M.; STAGLJAR, I.; TRAEBERT, M.; BACIC, D.; BIBER, J.; MURER, H. Interaction of the type IIa Na/Pi cotransporter with PDZ proteins. J. Biol. Chem., v. 276, p. 92069213, 2001.

GUILLEMOT, L.; LEVY, A.; RAYMONDJEAN, M.; ROTHHUT, B. Angiotensin II-induced transcriptional activation of the cyclin D1 gene is mediated by Egr-1 in CHO-AT(1A) cells. J. Biol. Chem., v. 276, p. 39394-39403, 2001. 
GUILLEMOT, L.; LEVY, A.; ZHAO, Z. J.; BEREZIAT, G.; ROTHHUT, B. The protein-tyrosine phosphatase SHP-2 is required during angiotensin II-mediated activation of cyclin D1 promoter in CHO-AT1A cells. J. Biol. Chem., v. 275, p. 26349-26358, 2000.

HAITHCOCK D.; JIAO, H.; CUI, X. L.; HOPFER, U.; DOUGLAS, J. G. Renal proximal tubular AT2 receptor: signaling and transport. J. Am. Soc. Nephrol., v. 10, p. S69-S74, 1999. Suppl 11.

HAN, H. J.; PARK, S. H.; KOH, H. J.; TAUB, M. Mechanism of regulation of Na+ transport by angiotensin II in primary renal cells. Kidney Int., v. 57, p. 2457-2467, 2000.

HARRIS, P. J.; YOUNG, J. A. Dose-dependent stimulation and inhibition of proximal tubular sodium reabsorption by angiotensin II in the rat kidney. Pflugers Arch., v. 367, p. 295-297, 1977.

HARRIS, R. C.; HOMMA, T.; JACOBSON, H. R.; CAPDEVILA, J. Epoxyeicosatrienoic acids activate $\mathrm{Na}+\mathrm{H}+$ exchange and are mitogenic in cultured rat glomerular mesangial cells. J. Cell Physiol., v. 144, p. 429-437, 1990.

HAULICA, I.; BILD, W.; SERBAN, D. N. Angiotensin peptides and their pleiotropic actions. J. Renin. Angiotensin. Aldosterone. Syst., v. 6, p. 121-131, 2005.

HAUS-SEUFFERT, P.; MEISTERERNST, M. Mechanisms of transcriptional activation of cAMP-responsive element-binding protein CREB. Mol. Cell Biochem., v. 212, p. 5-9, 2000.

HAWES, B. E.; LUTTRELL, L. M.; VAN, B. T.; LEFKOWITZ, R. J. Phosphatidylinositol 3kinase is an early intermediate in the $\mathrm{G}$ beta gamma-mediated mitogen-activated protein kinase signaling pathway. J. Biol. Chem., v. 271, p. 12133-12136, 1996.

HE P.; KLEIN, J.; YUN, C. C. Activation of Na+/H+ exchanger NHE3 by angiotensin II is mediated by inositol 1,4,5-triphosphate (IP3) receptor-binding protein released with IP3 (IRBIT) and $\mathrm{Ca} 2+/$ calmodulin-dependent protein kinase II. J. Biol. Chem., v. 285, p. 27869-27878, 2010. 
HE P.; ZHANG, H.; YUN, C. C. IRBIT, inositol 1,4,5-triphosphate (IP3) receptor-binding protein released with IP3, binds $\mathrm{Na}+\mathrm{H}+$ exchanger NHE3 and activates NHE3 activity in response to calcium. J. Biol. Chem., v. 283, p. 33544-33553, 2008.

HEIN, L.; MEINEL, L.; PRATT, R. E.; DZAU, V. J.; KOBILKA, B. K. Intracellular trafficking of angiotensin II and its AT1 and AT2 receptors: evidence for selective sorting of receptor and ligand. Mol. Endocrinol., v. 11, p. 1266-1277, 1997.

HORITA, S.; ZHENG, Y.; HARA, C.; YAMADA, H.; KUNIMI, M.; TANIGUCHI, S.; UWATOKO, S.; SUGAYA, T.; GOTO, A.; FUJITA, T.; SEKI, G. Biphasic regulation of Na+HCO3 cotransporter by angiotensin II type 1A receptor. Hypertension, v. 40, p. 707-712, 2002.

HOUILlIER, P.; CHAMBREY, R.; ACHARD, J. M.; FROISSART, M.; POGGIOLI, J.; PAILLARD, M. Signaling pathways in the biphasic effect of angiotensin II on apical $\mathrm{Na} / \mathrm{H}$ antiport activity in proximal tubule. Kidney Int., v. 50, p. 1496-1505, 1996.

HUNYADY, L.; CATT, K. J. Pleiotropic AT1 receptor signaling pathways mediating physiological and pathogenic actions of angiotensin II. Mol. Endocrinol., v. 20, p. 953-970, 2006.

JANECKI, A. J.; JANECKI, M.; AKHTER, S.; DONOWITZ, M. Basic fibroblast growth factor stimulates surface expression and activity of $\mathrm{Na}(+) / \mathrm{H}(+)$ exchanger NHE3 via mechanism involving phosphatidylinositol 3-kinase. J. Biol. Chem., v. 275, p. 8133-8142, 2000.

JOHNSON, R. J.; ALPERS, C. E.; YOSHIMURA, A.; LOMBARDI, D.; PRITZL, P.; FLOEGE, J.; SCHWARTZ, S. M. Renal injury from angiotensin II-mediated hypertension. Hypertension, v. 19, p. 464-474, 1992.

JOURDAIN, M.; AMIEL, C.; FRIEDLANDER, G. Modulation of Na-H exchange activity by angiotensin II in opossum kidney cells. Am. J. Physiol., v. 263, C1141-C1146 1992.

KANDASAMY, R. A.; ORLOWSKI, J. Genomic organization and glucocorticoid transcriptional activation of the rat Na+/H+ exchanger Nhe3 gene. J. Biol. Chem., v. 271, p. 10551-10559, 1996. 
KHURANA, S.; NATH, S. K.; LEVINE, S. A.; BOWSER, J. M.; TSE, C. M.; COHEN, M. E.; DONOWITZ, M. Brush border phosphatidylinositol 3-kinase mediates epidermal growth factor stimulation of intestinal $\mathrm{NaCl}$ absorption and $\mathrm{Na}+\mathrm{H}+$ exchange. J. Biol. Chem., v. 271, p. 99199927, 1996.

KIELA, P. R.; HINES, E. R.; COLLINS, J. F.; GHISHAN, F. K. Regulation of the rat NHE3 gene promoter by sodium butyrate. Am. J. Physiol. Gastrointest. Liver Physiol., v. 281, p. G947G956 2001.

KIELA, P. R.; LESUEUR, J.; COLLINS, J. F.; GHISHAN, F. K. Transcriptional regulation of the rat NHE3 gene. Functional interactions between GATA-5 and Sp family transcription factors. J. Biol. Chem., v. 278, p. 5659-5668, 2003.

KIM, J. H.; LEE-KWON, W.; PARK, J. B.; RYU, S. H.; YUN, C. H.; DONOWITZ, M. Ca(2+)dependent inhibition of $\mathrm{Na}+\mathrm{H}+$ exchanger 3 (NHE3) requires an NHE3-E3KARP-alpha-actinin-4 complex for oligomerization and endocytosis. J. Biol. Chem., v. 277, p. 23714-23724, 2002.

KOBORI, H.; NANGAKU, M.; NAVAR, L. G.; NISHIYAMA, A. The intrarenal reninangiotensin system: from physiology to the pathobiology of hypertension and kidney disease. Pharmacol. Rev., v. 59, p. 251-287, 2007a.

KOBORI, H.; OZAWA, Y.; SATOU, R.; KATSURADA, A.; MIYATA, K.; OHASHI, N.; HASE, N.; SUZAKI, Y.; SIGMUND, C. D.; NAVAR, L. G. Kidney-specific enhancement of ANG II stimulates endogenous intrarenal angiotensinogen in gene-targeted mice. Am. J. Physiol. Renal Physiol., v. 293, p. F938-F945, 2007b.

KOCINSKY, H. S.; GIRARDI, A. C.; BIEMESDERFER, D.; NGUYEN, T.; MENTONE, S.; ORLOWSKI, J.; ARONSON, P. S. Use of phospho-specific antibodies to determine the phosphorylation of endogenous $\mathrm{Na}+\mathrm{H}+$ exchanger NHE3 at PKA consensus sites. Am. J. Physiol. Renal Physiol., v. 289, p. F249-F258, 2005.

KOHOUT, T. A.; LEFKOWITZ, R. J. Regulation of G protein-coupled receptor kinases and arrestins during receptor desensitization. Mol. Pharmacol., v. 63, p. 9-18, 2003. 
KUMAR, R.; SINGH, V. P.; BAKER, K. M. The intracellular renin-angiotensin system: a new paradigm. Trends Endocrinol. Metab., v. 18, p. 208-214, 2007.

KURASHIMA, K.; SZABO, E. Z.; LUKACS, G.; ORLOWSKI, J.; GRINSTEIN, S. Endosomal recycling of the $\mathrm{Na}+\mathrm{H}+$ exchanger NHE3 isoform is regulated by the phosphatidylinositol 3kinase pathway. J. Biol. Chem., v. 273, p. 20828-20836, 1998.

KURASHIMA, K.; YU, F. H.; CABADO, A. G.; SZABO, E. Z.; GRINSTEIN, S.; ORLOWSKI, J. Identification of sites required for down-regulation of $\mathrm{Na}+\mathrm{H}+$ exchanger NHE3 activity by cAMP-dependent protein kinase. phosphorylation-dependent and -independent mechanisms. J. Biol. Chem., v. 272, p. 28672-28679, 1997.

LAMPRECHT, G.; WEINMAN, E. J.; YUN, C. H. The role of NHERF and E3KARP in the cAMP-mediated inhibition of NHE3. J. Biol. Chem., v. 273, p. 29972-29978, 1998.

LEE, S. H.; KIM, T.; PARK, E. S.; YANG, S.; JEONG, D.; CHOI, Y.; RHO, J. NHE10, an osteoclast-specific member of the $\mathrm{Na}+\mathrm{H}+$ exchanger family, regulates osteoclast differentiation and survival [corrected]. Biochem. Biophys. Res. Commun., v. 369, p. 320-326, 2008.

LEE-KWON, W.; JOHNS, D. C.; CHA, B.; CAVET, M.; PARK, J.; TSICHLIS, P.; DONOWITZ, M. Constitutively active phosphatidylinositol 3-kinase and AKT are sufficient to stimulate the epithelial Na+/H+ exchanger 3. J. Biol. Chem., v. 276, p. 31296-31304, 2001.

LEHOUX, J. G.; LEFEBVRE, A. Transcriptional activity of the hamster CYP11B2 promoter in NCI-H295 cells stimulated by angiotensin II, potassium, forskolin and bisindolylmaleimide. J. Mol. Endocrinol., v. 20, p. 183-191, 1998.

LEONG, P. K.; DEVILLEZ, A.; SANDBERG, M. B.; YANG, L. E.; YIP, D. K.; KLEIN, J. B.; MCDONOUGH, A. A. Effects of ACE inhibition on proximal tubule sodium transport. Am. J. Physiol. Renal Physiol., v. 290, p. F854-F863, 2006.

LEONG, P. K.; YANG, L. E.; HOLSTEIN-RATHLOU, N. H.; MCDONOUGH, A. A. Angiotensin II clamp prevents the second step in renal apical NHE3 internalization during acute hypertension. Am. J. Physiol. Renal Physiol., v. 283, p. F1142-F1150, 2002. 
LI, X.; ZHANG, H.; CHEONG, A.; LEU, S.; CHEN, Y.; ELOWSKY, C. G.; DONOWITZ, M. Carbachol regulation of rabbit ileal brush border Na+-H+ exchanger 3 (NHE3) occurs through changes in NHE3 trafficking and complex formation and is Src dependent. J. Physiol., v. 556, p. 791-804, 2004.

LI, X. C.; ZHUO, J. L. Intracellular ANG II directly induces in vitro transcription of TGF-beta1, MCP-1, and NHE-3 mRNAs in isolated rat renal cortical nuclei via activation of nuclear AT1a receptors. Am. J. Physiol. Cell Physiol., v. 294, p. C1034-C1045, 2008.

LICEA, H.; WALTERS, M. R.; NAVAR, L. G. Renal nuclear angiotensin II receptors in normal and hypertensive rats. Acta Physiol. Hung., v. 89, p. 427-438, 2002.

LIU, F. Y.; COGAN, M. G. Angiotensin II stimulates early proximal bicarbonate absorption in the rat by decreasing cyclic adenosine monophosphate. J. Clin. Invest., v. 84, p. 83-91, 1989.

LOOK, D. C.; PELlETIER, M. R.; TIDWELL, R. M.; ROSWIT, W. T.; HOLTZMAN, M. J. Stat1 depends on transcriptional synergy with Sp1. J. Biol. Chem., v. 270, p. 30264-30267, 1995.

LU, D.; YANG, H.; RAIZADA, M. K. AT1 receptor-mediated nuclear translocation of Raf-1 in brain neurons. J. Neurochem., v. 70, p. 424-427, 1998.

LUTKEN, S. C.; KIM, S. W.; JONASSEN, T. E.; MARPLES, D.; KNEPPER, M. A.; KWON, T. H.; FROKIAER, J.; NIELSEN, S. Changes of renal AQP2, ENaC, and NHE3 in experimentally induced heart failure: response to angiotensin II AT1 receptor blockade. Am. J. Physiol. Renal Physiol., v. 297, p. F1678-F1688, 2009.

LUTTRELL, L. M.; LEFKOWITZ, R. J. The role of beta-arrestins in the termination and transduction of G-protein-coupled receptor signals. J. Cell Sci., v. 115, p. 455-465, 2002.

LUTTRELl, L. M.; ROUDABUSH, F. L.; CHOY, E. W.; MILLER, W. E.; FIELD, M. E.; PIERCE, K. L.; LEFKOWITZ, R. J. Activation and targeting of extracellular signal-regulated kinases by beta-arrestin scaffolds. Proc. Natl. Acad. Sci. U.S.A, v. 98, p. 2449-2454, 2001. 
MALAKOOTI, J.; MEMARK, V. C.; DUDEJA, P. K.; RAMASWAMY, K. Molecular cloning and functional analysis of the human $\mathrm{Na}(+) / \mathrm{H}(+)$ exchanger NHE3 promoter. Am. J. Physiol. Gastrointest. Liver Physiol., v. 282, p. G491-G500, 2002.

MALAKOOTI, J.; SANDOVAL, R.; AMIN, M. R.; CLARK, J.; DUDEJA, P. K.; RAMASWAMY, K. Transcriptional stimulation of the human NHE3 promoter activity by PMA: PKC independence and involvement of the transcription factor EGR-1. Biochem. J., v. 396, p. 327-336, 2006.

MARRERO, M. B.; BANES-BERCELI, A. K.; STERN, D. M.; EATON, D. C. Role of the JAK/STAT signaling pathway in diabetic nephropathy. Am. J. Physiol. Renal Physiol., v. 290, F762-F768, 2006.

MARRERO, M. B.; SCHIEFFER, B.; PAXTON, W. G.; HEERDT, L.; BERK, B. C.; DELAFONTAINE, P.; BERNSTEIN, K. E. Direct stimulation of Jak/STAT pathway by the angiotensin II AT1 receptor. Nature, v. 375, p. 247-250, 1995.

MEHTA, P. K.; GRIENDLING, K. K. Angiotensin II cell signaling: physiological and pathological effects in the cardiovascular system. Am. J. Physiol. Cell Physiol., v. 292, p. C82C97, 2007.

MILANINI-MONGIAT, J.; POUYSSEGUR, J.; PAGES, G. Identification of two Sp1 phosphorylation sites for $\mathrm{p} 42 / \mathrm{p} 44$ mitogen-activated protein kinases: their implication in vascular endothelial growth factor gene transcription. J. Biol. Chem., v. 277, p. 20631-20639, 2002.

MOE, O. W. Acute regulation of proximal tubule apical membrane $\mathrm{Na} / \mathrm{H}$ exchanger NHE-3: role of phosphorylation, protein trafficking, and regulatory factors. J. Am. Soc. Nephrol., v. 10, p. 2412-2425, 1999.

MOE, O. W.; AMEMIYA, M.; YAMAJI, Y. Activation of protein kinase A acutely inhibits and phosphorylates Na/H exchanger NHE-3. J. Clin. Invest., v. 96, p. 2187-2194, 1995.

MONTROSE, M. H.; MURER, H. Polarity and kinetics of $\mathrm{Na}(+)-\mathrm{H}+$ exchange in cultured opossum kidney cells. Am. J. Physiol., v. 259, p. C121-C133, 1990. 
MURER, H.; HOPFER, U.; KINNE, R. Sodium/proton antiport in brush-border-membrane vesicles isolated from rat small intestine and kidney. Biochem. J., v. 154, p. 597-604, 1976.

MUSCH, M. W.; LI, Y. C.; CHANG, E. B. Angiotensin II directly regulates intestinal epithelial NHE3 in Caco2BBE cells. BMC. Physiol., v. 9, p. 5-12, 2009.

NAVAR, L. G.; HARRISON-BERNARD, L. M.; IMIG, J. D.; WANG, C. T.; CERVENKA, L.; MITCHELL, K. D. Intrarenal angiotensin II generation and renal effects of AT1 receptor blockade. J. Am. Soc. Nephrol., v. 10, p. S266-S272, 1999. Suppl. 12.

NIGGLI, V.; ROSSY, J. Ezrin/radixin/moesin: versatile controllers of signaling molecules and of the cortical cytoskeleton. Int. J. Biochem.Cell Biol., v. 40, p. 344-349, 2008.

NISHIMOTO, M.; TAKAI, S.; KIM, S.; JIN, D.; YUDA, A.; SAKAGUCHI, M.; YAMADA, M.; SAWADA, Y.; KONDO, K.; ASADA, K.; IWAO, H.; SASAKI, S.; MIYAZAKI, M. Significance of chymase-dependent angiotensin II-forming pathway in the development of vascular proliferation. Circulation, v. 104, p. 1274-1279, 2001.

ORLOWSKI, J.; GRINSTEIN, S. Diversity of the mammalian sodium/proton exchanger SLC9 gene family. Pflugers Arch., v. 447, p. 549-565, 2004.

pGL3 basic, ([2010]). Disponível em http://www.promega.com/tbs/tm033/tm033.pdf.

POGGIOLI, J.; LAZAR, G.; HOUILLIER, P.; GARDIN, J. P.; ACHARD, J. M.; PAILLARD, M. Effects of angiotensin II and nonpeptide receptor antagonists on transduction pathways in rat proximal tubule. Am. J. Physiol., v. 263, p. C750-C758, 1992.

POLLOCK, A. S.; WARNOCK, D. G.; STREWLER, G. J. Parathyroid hormone inhibition of Na+-H+ antiporter activity in a cultured renal cell line. Am. J. Physiol., v. 250, p. F217-F225, 1986.

pRL, ([2010)]. Disponível em http://www.promega.com/tbs/tb550/tb550.pdf. 
RINK, T. J.; TSIEN, R. Y.; POZZAN, T. Cytoplasmic pH and free Mg2+ in lymphocytes. J. Cell Biol., v. 95, p. 189-196, 1982.

RUIZ-ORTEGA, M.; LORENZO, O.; SUZUKI, Y.; RUPEREZ, M.; EGIDO, J. Proinflammatory actions of angiotensins. Curr. Opin. Nephrol. Hypertens., v. 10, p. 321-329, 2001.

SACCOMANI, G.; MITCHELL, K. D.; NAVAR, L. G. Angiotensin II stimulation of Na(+)-H+ exchange in proximal tubule cells. Am. J. Physiol., v. 258, p. F1188-F1195, 1990.

SAITO, Y.; BERK, B. C. Transactivation: a novel signaling pathway from angiotensin II to tyrosine kinase receptors. J. Mol. Cell Cardiol., v. 33, p. 3-7, 2001.

SARDET, C.; FRANCHI, A.; POUYSSEGUR, J. Molecular cloning, primary structure, and expression of the human growth factor-activatable $\mathrm{Na}+\mathrm{H}+$ antiporter. Cell, v. 56, p. 271-280, 1989.

SCHELLING, J. R.; LINAS, S. L. Angiotensin II-dependent proximal tubule sodium transport requires receptor-mediated endocytosis. Am. J. Physiol., v. 266, p. C669-C675, 1994.

SCHIEFFER, B.; PAXTON, W. G.; CHAI, Q.; MARRERO, M. B.; BERNSTEIN, K. E. Angiotensin II controls p21ras activity via pp60c-src. J. Biol. Chem., v. 271, p. 10329-10333, 1996.

SCHULTHEIS, P. J.; CLARKE, L. L.; MENETON, P.; MILLER, M. L.; SOLEIMANI, M.; GAWENIS, L. R.; RIDDLE, T. M.; DUFFY, J. J.; DOETSCHMAN, T.; WANG, T.; GIEBISCH, G.; ARONSON, P. S.; LORENZ, J. N.; SHULL, G. E. Renal and intestinal absorptive defects in mice lacking the NHE3 Na+/H+ exchanger. Nat. Genet., v. 19, p. 282-285, 1998.

SCHUSTER, V. L.; KOKKO, J. P.; JACOBSON, H. R. Angiotensin II directly stimulates sodium transport in rabbit proximal convoluted tubules. J. Clin. Invest, v. 73, p. 507-515, 1984. 
SCHWARK, J. R.; JANSEN, H. W.; LANG, H. J.; KRICK, W.; BURCKHARDT, G.; HROPOT, M. S3226, a novel inhibitor of $\mathrm{Na}+\mathrm{H}+$ exchanger subtype 3 in various cell types. Pflugers Arch., v. 436, p. 797-800, 1998.

SCOTT, R. O.; THELIN, W. R.; MILGRAM, S. L. A novel PDZ protein regulates the activity of guanylyl cyclase C, the heat-stable enterotoxin receptor. J. Biol. Chem., v. 277, p. 22934-22941, 2002.

SOLEIMANI, M.; BOOKSTEIN, C.; MCATEER, J. A.; HATTABAUGH, Y. J.; BIZAL, G. L.; MUSCH, M. W.; VILLEREAL, M.; RAO, M. C.; HOWARD, R. L.; CHANG, E. B. Effect of high osmolality on $\mathrm{Na}+\mathrm{H}+$ exchange in renal proximal tubule cells. J. Biol. Chem., v. 269, p. 15613-15618, 1994.

SPECTOR, A. A.; NORRIS, A. W. Action of epoxyeicosatrienoic acids on cellular function. Am. J. Physiol. Cell Physiol., v. 292, p. C996-1012, 2007.

SU, H. W.; WANG, S. W.; GHISHAN, F. K.; KIELA, P. R.; TANG, M. J. Cell confluencyinduced Stat3 activation regulates NHE3 expression by recruiting Sp1 and Sp3 to the proximal NHE3 promoter region during epithelial dome formation. Am. J. Physiol. Cell Physiol., v. 296, p. C13-C24, 2009.

SUSKE, G. The Sp-family of transcription factors. Gene, v. 238, p. 291-300, 1999.

TAN, N. Y.; KHACHIGIAN, L. M. Sp1 phosphorylation and its regulation of gene transcription. Mol. Cell Biol., v. 29, p. 2483-2488, 2009.

TANG, S. S.; ROGG, H.; SCHUMACHER, R.; DZAU, V. J. Characterization of nuclear angiotensin-II-binding sites in rat liver and comparison with plasma membrane receptors. Endocrinology, v. 131, p. 374-380, 1992.

THEKKUMKARA, T.; LINAS, S. L. Role of internalization in AT(1A) receptor function in proximal tubule epithelium. Am. J. Physiol. Renal Physiol., v. 282, p. F623-F629, 2002. 
THOMAS, J. A.; BUCHSBAUM, R. N.; ZIMNIAK, A.; RACKER, E. Intracellular pH measurements in Ehrlich ascites tumor cells utilizing spectroscopic probes generated in situ. Biochemistry, v. 18, p. 2210-2218, 1979.

THOMAS, W. G.; QIAN, H. Arresting angiotensin type 1 receptors. Trends Endocrinol. Metab, v. 14, p. 130-136, 2003.

TIMMERMANS, P. B.; WONG, P. C.; CHIU, A. T.; HERBLIN, W. F.; BENFIELD, P.; CARINI, D. J.; LEE, R. J.; WEXLER, R. R.; SAYE, J. A.; SMITH, R. D. Angiotensin II receptors and angiotensin II receptor antagonists. Pharmacol. Rev., v. 45, p. 205-251, 1993.

TOUYZ, R. M.; BERRY, C. Recent advances in angiotensin II signaling. Braz. J. Med. Biol. Res., v. 35, p. 1001-1015, 2002.

TURBAN, S.; BEUTLER, K. T.; MORRIS, R. G.; MASILAMANI, S.; FENTON, R. A.; KNEPPER, M. A.; PACKER, R. K. Long-term regulation of proximal tubule acid-base transporter abundance by angiotensin II. Kidney Int., v. 70, p. 660-668, 2006.

VENEPALLY, P.; WATERMAN, M. R. Two Sp1-binding sites mediate cAMP-induced transcription of the bovine CYP11A gene through the protein kinase A signaling pathway. J. Biol. Chem., v. 270, p. 25402-25410, 1995.

WADE, J. B.; LIU, J.; COLEMAN, R. A.; CUNNINGHAM, R.; STEPLOCK, D. A.; LEEKWON, W.; PALLONE, T. L.; SHENOLIKAR, S.; WEINMAN, E. J. Localization and interaction of NHERF isoforms in the renal proximal tubule of the mouse. Am. J. Physiol. Cell Physiol., v. 285, p. C1494-C1503, 2003.

WADE, J. B.; WELling, P. A.; DONOWITZ, M.; SHENOLIKAR, S.; WEINMAN, E. J. Differential renal distribution of NHERF isoforms and their colocalization with NHE3, ezrin, and ROMK. Am. J. Physiol. Cell Physiol., v. 280, p. C192-C198, 2001.

WANG, T.; CHAN, Y. L. Mechanism of angiotensin II action on proximal tubular transport. J. Pharmacol. Exp.Ther., v. 252, p. 689-695, 1990. 
WEINMAN, E. J.; SHENOLIKAR, S. Protein kinase C activates the renal apical membrane $\mathrm{Na}+/ \mathrm{H}+$ exchanger. J. Membr. Biol., v. 93, p. 133-139, 1986.

WEN, A. Y.; SAKAMOTO, K. M.; MILLER, L. S. The role of the transcription factor CREB in immune function. J. Immunol., v. 185, p. 6413-6419, 2010.

WIEDERKEHR, M. R.; ZHAO, H.; MOE, O. W. Acute regulation of Na/H exchanger NHE3 activity by protein kinase C: role of NHE3 phosphorylation. Am. J. Physiol., v. 276, p. C1205C1217, 1999.

WOLF, G.; WENZEL, U. O. Angiotensin II and cell cycle regulation. Hypertension, v. 43, p. 693-698, 2004.

WOLF, G.; ZIYADEH, F. N.; ZAHNER, G.; STAHL, R. A. Angiotensin II-stimulated expression of transforming growth factor beta in renal proximal tubular cells: attenuation after stable transfection with the c-mas oncogene. Kidney Int., v. 48, p. 1818-1827, 1995.

XIE, M. H.; LIU, F. Y.; WONG, P. C.; TIMMERMANS, P. B.; COGAN, M. G. Proximal nephron and renal effects of DuP 753, a nonpeptide angiotensin II receptor antagonist. Kidney Int., v. 38, p. 473-479, 1990.

XU, L.; DIXIT, M. P.; NULlMEYER, K. D.; XU, H.; KIELA, P. R.; LYNCH, R. M.; GHISHAN, F. K. Regulation of $\mathrm{Na}+\mathrm{H}+$ exchanger-NHE3 by angiotensin-II in OKP cells. Biochim. Biophys. Acta, v. 1758, p. 519-526, 2006.

YANG, L.; LEONG, P. K.; CHEN, J. O.; PATEL, N.; HAMM-ALVAREZ, S. F.; MCDONOUGH, A. A. Acute hypertension provokes internalization of proximal tubule NHE3 without inhibition of transport activity. Am. J. Physiol. Renal Physiol., v. 282, p. F730-F740, 2002.

YANG, L. E.; LEONG, P. K.; MCDONOUGH, A. A. Reducing blood pressure in SHR with enalapril provokes redistribution of NHE3, NaPi2, and NCC and decreases $\mathrm{NaPi} 2$ and ACE abundance. Am. J. Physiol. Renal Physiol., v. 293, p. F1197-F1208, 2007. 
YANG, L. E.; MAUNSBACH, A. B.; LEONG, P. K.; MCDONOUGH, A. A. Differential traffic of proximal tubule $\mathrm{Na}+$ transporters during hypertension or PTH: NHE3 to base of microvilli vs. NaPi2 to endosomes. Am. J. Physiol. Renal Physiol., v. 287, p. F896-F906, 2004.

YANG, L. E.; SANDBERG, M. B.; CAN, A. D.; PIHAKASKI-MAUNSBACH, K.; MCDONOUGH, A. A. Effects of dietary salt on renal Na+ transporter subcellular distribution, abundance, and phosphorylation status. Am. J. Physiol. Renal Physiol., v. 295, p. F1003-F1016, 2008.

YIN, G.; YAN, C.; BERK, B. C. Angiotensin II signaling pathways mediated by tyrosine kinases. Int. J. Biochem. Cell Biol., v. 35, p. 780-783, 2003.

ZACHOS, N. C.; TSE, M.; DONOWITZ, M. Molecular physiology of intestinal Na+/H+ exchange. Annu. Rev. Physiol., v. 67, p. 411-443, 2005.

ZACHOS, N. C.; VAN ROSSUM, D. B.; LI, X.; CARAVEO, G.; SARKER, R.; CHA, B.; MOHAN, S.; DESIDERIO, S.; PATTERSON, R. L.; DONOWITZ, M. Phospholipase C-gamma binds directly to the $\mathrm{Na}+\mathrm{H}+$ exchanger 3 and is required for calcium regulation of exchange activity. J. Biol. Chem., v. 284, p. 19437-19444, 2009.

ZHAO, H.; SHIUE, H.; PALKON, S.; WANG, Y.; CULLINAN, P.; BURKHARDT, J. K.; MUSCH, M. W.; CHANG, E. B.; TURNER, J. R. Ezrin regulates NHE3 translocation and activation after Na+-glucose cotransport. Proc. Natl. Acad. Sci. U.S.A, v. 101, p. 9485-9490, 2004.

ZHAO, H.; WIEDERKEHR, M. R.; FAN, L.; COLLAZO, R. L.; CROWDER, L. A.; MOE, O. W. Acute inhibition of $\mathrm{Na} / \mathrm{H}$ exchanger NHE-3 by cAMP. Role of protein kinase a and NHE-3 phosphoserines 552 and 605. J. Biol.Chem., v. 274, p. 3978-3987, 1999.

ZHENG, Y.; HORITA, S.; HARA, C.; KUNIMI, M.; YAMADA, H.; SUGAYA, T.; GOTO, A.; FUJITA, T.; SEKI, G. Biphasic regulation of renal proximal bicarbonate absorption by luminal AT(1A) receptor. J. Am. Soc. Nephrol., v. 14, p. 1116-1122, 2003. 